\title{
On Motion Control of Linear Incremental Hydraulic Actuators
}

\section{Martin Hochwallner}

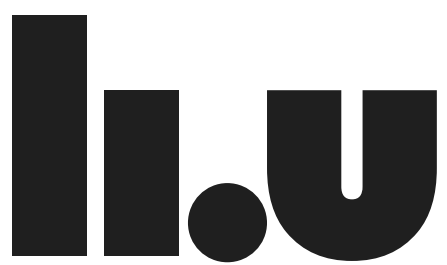

LINKÖPING UNIVERSITY

Division of Fluid and Mechatronic Systems (Flumes)

Department of Management and Engineering Linköping University, SE-581 83 Linköping, Sweden 


\section{Cover:}

The front cover page shows a stylized rope/rod climber.

This refers to the fact that the motion of linear incremental hydraulic actuators has similarities to rope climbing.

Designed by Gudrun Geiblinger <http://geiblinger.at/>

Copyright @ Martin Hochwallner, 2017

On Motion Control of Linear Incremental Hydraulic Actuators

ISBN 978-91-7685-425-9

ISSN 0345-7524

\section{Distributed by:}

Division of Fluid and Mechatronic Systems (Flumes)

Department of Management and Engineering

Linköping University

SE-581 83 Linköping, Sweden

Printed in Sweden by LiU-Tryck, Linköping 2017. 
To Liselott 



\section{Abstract}

Linear Incremental Hydraulic Actuators combine one or more short-stroke cylinders, and two or more engaging/disengaging mechanisms into one actuator with long, medium, or even unlimited stroke length. The motion of each single short-stroke actuator concatenated by the engaging/disengaging mechanisms forms the motion of the linear incremental hydraulic actuator.

The patterns of how these motions are concatenated form the gaits of a specific linear incremental hydraulic actuator. Linear incremental hydraulic actuators may have more than one gait. In an application, the gaits may be combined to achieve optimal performance at various operating points.

The distinguishing characteristic of linear incremental hydraulic actuators is the incremental motion. The term incremental actuator is seen as analogous to the incremental versus absolute position sensor. Incremental actuators realize naturally relative positioning. Incremental motion means also that the behavior does not depend on an absolute position but only on the relative position within a cycle or step.

Incremental actuators may realize discrete incremental or continuous incremental motion. Discrete incremental actuators can only approach discrete positions, whereby stepper drives are one prominent example. In contrast, continuous incremental actuators may approach any position. Linear electric motors are one example of continuous incremental actuators.

The actuator has no inherent limitation in stroke length, as every step or cycle adds only to the state at the beginning of the step or cycle and does not depend on the absolute position. This led to the alternative working title Hydraulic Infinite Linear Actuator.

Linear incremental hydraulic actuator provides long stroke, high force, and linear motion and has the potential to

- decrease the necessary resource usage,

- minimize environmental impact, e.g. from potential oil spillage,

- extend the range of feasible products: longer, stiffer, better, etc. 
This thesis presents an analysis of the characteristics and properties of linear incremental hydraulic actuators as well as the gaits and possible realizations of some gaits. The gait for continuous, smooth motion with two cylinders is comprehensively studied and a control concept for the tracking problem is proposed. The control concept encapsulates the complexity of the linear incremental hydraulic actuator so that an application does not have to deal with it. One other gait, the ballistic gait, which realizes fast, energy-efficient motion, enabling energy recuperation is studied. 


\section{Sammanfattning (SV)}

Linjära inkrementella hydrauliska aktuatorer (engelska: linear incremental hydraulic actuators) kombinerar en eller flera korta cylindrar och två eller fler ingrepps- / urkopplingsmekanismer till ett manövrdon med långa, medellånga eller till och med obegränsad slaglängd. Förflyttningen av varje enskilt slag sammanfogas av ingrepps- / urkopplingsmekanismerna som utgör rörelsen av den linjära inkrementella hydrauliska aktuatorn. En specifik kombination av dessa rörelser bildar en gångart av en specifik linjär inkrementell hydraulisk aktuator. Linjär inkrementell hydraulisk aktuator kan ha fler än en gångart. I en tillämpning kan gångarterna kombineras för att uppnå optimal prestanda i olika driftspunkter. Den karakteristiska egenskapen hos en linjär inkrementell hydraulisk aktuator är den inkrementella rörelsen. Termen inkrementell aktuator ses analogt med inkrementell positionsgivare jämfört med absolut positionsgivare. Inkrementell aktuator realiserar naturligt en relativ positionering. Inkrementell rörelse innebär också att beteendet inte beror på en absolut position utan endast på det relativa läget inom en cykel eller ett steg. Inkrementell aktuator kan realiseras i diskret eller kontinuerlig rörelse. Diskreta inkrementella aktuatorer kan endast anta diskreta positioner, varigenom stegmotorer är ett framträdande exempel. I kontrast kan kontinuerliga inkrementella aktuatorer anta vilken position som helst. Manöverdonet har ingen inbyggd begränsning i slaglängd, varje steg läggs endast till i början av cykeln och beror inte på det absoluta läget. Det ledde till den alternativa arbetstiteln hydraulic infinit linjear actuator.

Linjär inkrementell hydraulisk aktuator ger långa slag, stora krafter, linjära rörelser och har potential att

- minska nödvändig resursanvändning,

- minimera miljöpåverkan som potentiellt oljeutsläpp,

- och bredda utbudet av möjliga produkter: längre, styvare, bättre,. . . 
Denna avhandling presenterar en analys av egenskaperna hos linjära inkrementella hydrauliska aktuatorer till lika de olika gångarterna och möjliga realisationer av vissa gångarter. Gångarten för kontinuerlig jämn rörelse med två cylindrar är studerat och ett reglerkoncept för spårningsproblemet föreslås. Kontrollkonceptet beaktar komplexiteten hos linjära inkrementella hydrauliska aktuatorer så att en tillämpning inte behöver hantera detta. En annan gångart som har studerats är den ballistiska gångarten. Denna gångart realiserar en snabb och energieffektiv rörelse som också möjliggör energiåtervinning. 


\section{Acknowledgements}

The work upon which this thesis is based was conducted at the Division of Fluid and Mechatronic Systems (Flumes), a division of the Department of Management and Engineering at Linköping University. My supervisor, Petter Krus, Head of Division, I want to thank for making the thesis possible and for all his support and interesting discussions. Stort tack! Thanks also to Lie Pablo Grala Pinto for your support as co-author. Muito obrigado! Due to the people here, especially my colleagues at Flumes, my life at LiU has been interesting and fun from the first day. I want to single out Peter Nordin, Mr Hopsan, for his dedication in developing Hopsan, the simulation software I used for this work.

Thanks go to my former colleagues at the Linz Center of Mechatronics GmbH (LCM) and the Institute of Machine Design and Hydraulic Drives (IMH), Johannes Kepler Universität Linz, Austria. Rudolf Scheidl, thanks for making my guest visit at LiU possible and for all your support and inspiration. Vielen Dank! I am glad to have met many inspiring professors, teachers, and colleagues such as Andreas Kugi, Manfred Kaltenbacher, Siegfried Silber, and Rudolf Scheidl, to mention just a few of many.

Thanks also go to NoMagic, in particular Donatas Ugenskas, for providing Magic Draw, Cameo Systems Modeler and valuable support. Thanks to the team at National Instruments for all your fast and helpful support. Your extraordinary way of delivering equipment by jumping off the train on the eve of a weekend so a student could finish his thesis on time will never be forgotten. Gudrun Geiblinger, thanks for this incredible cover.

My parents Maria and Johann supported me to become an engineer from an early age. Vielen Dank! My second parents Marita and Hans welcomed me into their family. Tack för allt. And last but not least, sincere thanks go to my wife Liselott. To find a partner like you required and was well worth moving a few kilometers for.

Linköping, 2017
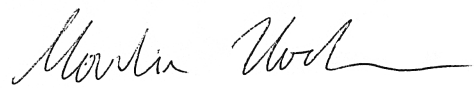

Martin Hochwallner 


\section{Appended Papers}

This dissertation is build on the following papers. Paper [I] presents a solution realizing smooth motion with the investigated actuator. This paper builds on the findings of and solves the problems presented in paper [III]. Paper [IV] analyses the characteristics of the investigated class of actuators. Paper [II] introduces an unconventional gait which realizes hydraulic-mechanical pulsefrequency modulation (PFM). The publications $[1 ; 2 ; 3 ; 4 ; 5 ; 6]$ are not included but show the background of the author.

The appended papers have been corrected for printing errors and the layout of the text and the figures has been adapted to the format of this book.

[I] Martin Hochwallner, Lie Pablo Grala Pinto, and Petter Krus, 2017 "Tracking Control for High Performance Motion of an Hydraulic Infinite Linear Actuator".

In: submitted to IEEE/ASME Transactions on Mechatronics (2017)

Martin Hochwallner is the main author. He come up with the idea and the concept, conducted the research, and was the manuscript writer.

Lie Pablo Grala Pinto and Petter Krus provided support and feedback.

[II] Martin Hochwallner and Petter Krus, 2017

"Hydraulic Infinite Linear Actuator - The Ballistic Gait - Digital HydroMechanical Motion".

In Proceedings of the 15th Scandinavian International Conference on Fluid Power, SICFP'17

Martin Hochwallner is the main author. He come up with the idea and the concept, conducted the research, and was the manuscript writer. Petter Krus provided support and feedback. 
[III] Martin Hochwallner and Petter Krus, 2016

"Motion Control Concepts for the Hydraulic Infinite Linear Actuator".

In Proceedings of the 9th FPNI PHD Symposium on Fluid Power. ISBN: 978-0-7918-5047-3

Martin Hochwallner is the main author. He come up with the idea and the concept, conducted the research, and was the manuscript writer.

Petter Krus provided support and feedback.

[IV] Martin Hochwallner, Magnus Landberg, and Petter Krus, 2016

"The Hydraulic Infinite Linear Actuator - properties relevant for control".

In Proceedings of the 10th International Fluid Power Conference (10. IFK), Vol. 3, pp. 411-424.

http://nbn-resolving.de/urn:nbn:de:bsz:14-qucosa-200646.

Martin Hochwallner is the main author. He come up with the idea and the concept, conducted the research, and was the manuscript writer.

Petter Krus provided support and feedback.

\section{Additional Papers and Publications}

[1] Martin Hochwallner, Matthias Hörl, Stefan Dierneder, and Rudolf Scheidl, 2011

"Some Aspects of SysML Application in the Reverse Engineering of Mechatronic Systems".

In: Computer Aided Systems Theory, EUROCAST 2011 - 13th International Conference, Revised Selected Papers. Vol. LNCS 6928. Lecture Notes in Computer Science. 2011, pp. 81-88. ISBN: 9783642275784. DOI: 10.1007/978-3-642-27579-1_11.

Martin Hochwallner is the main author. He come up with the idea and the concept, conducted the research, and was the manuscript writer.

Matthias Hörl was part of many intense discussion and provided feedback. Stefan Dierneder, and Rudolf Scheidl provided support and feedback.

The content was also presented at the conference "5th MODPROD Workshop 2011" in Linköping.

[2] Matthias Hörl, Martin Hochwallner, Stefan Dierneder, and Rudolf Scheidl, 2011

"Integration of SysML and Simulation Models for Mechatronic Systems". In: Computer Aided Systems Theory, EUROCAST 2011 - 13th International Conference, Revised Selected Papers. Vol. LNCS 6928. Lecture Notes in Computer Science. 2011, pp. 89-96. ISBN: 9783642275784. DOI: 10.1007/978-3-642-27579-1_12. 
Martin Hochwallner is the second author. He contributed substantially to the concept and content of the paper as there are the development process, Requirements Engineering, SysML, and the conceptual interface from the SysML to the CAD and FE model.

Matthias Hörl is the main author. Stefan Dierneder, and Rudolf Scheidl provided support and feedback.

The content was also presented at the conference "5th MODPROD Workshop 2011" in Linköping.

[3] Gernot Grabmair, Simon Mayr, Martin Hochwallner, and Markus Aigner, 2014

"Model based control design - A free tool-chain".

In: European Control Conference (ECC). Institute of Electrical and Electronics Engineers (IEEE), 2014. ISBN: 978-3-9524269-1-3. DOI: $10.1109 /$ ecc.2014.6862509.

Martin Hochwallner is the third author. He contributed the part of the paper about X2C. He is the developer of the Scilab/Xcos implementation of X2C. Gernot Grabmair and Simon Mayr are the main authors. Markus Aigner is the main developer of $\mathrm{X} 2 \mathrm{C}$.

[4] Martin Hochwallner, and Stefan Fragner, 2014

Presentation: "Experience made in Model Based Design with the Tool X2C in the Field of Controller Design in a Mechatronic Product Development Environment".

8th MODPROD Workshop 2014, in Linköping, Sweden

Martin Hochwallner is the presenter. He come up with the idea and the concept. Stefan Fragner provided support and feedback, and is a development team member and user of $\mathrm{X} 2 \mathrm{C}$.

[5] Magnus Landberg, Martin Hochwallner, and Petter Krus, 2015

"Novel Linear Hydraulic Actuator".

In: 2015 Proceedings of the ASME/BATH 2015 Symposium on Fluid Power and Motion Control (FPMC2015). ISBN: 978-0-7918-5723-6.

DOI: $10.1115 /$ fpmc2015-9604

Chicago, Illinois, United States

[6] Liselott Ericson, Samuel Kärnell, and Martin Hochwallner, 2017

"Experimental Investigation of a Displacement-controlled Hydrostatic Pump/Motor by Means of Rotating Valve Plate".

In Proceedings of the 15th Scandinavian International Conference on Fluid Power, SICFP'17

Martin Hochwallner provided support and feedback in the topics machine design, control, measurement / data acquisition. 


\section{Contents}

1 Introduction 1

1.1 Background / Motivation . . . . . . . . . . . . 2

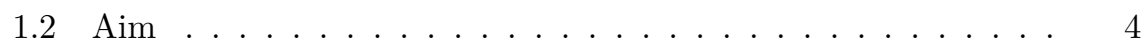

1.2.1 Research Questions . . . . . . . . . . . . . . . 4

1.3 Scope . . . . . . . . . . . . . . . . . . 5

1.4 Research Method . . . . . . . . . . . . . . . . . . . 6

2 State of the Art 9

2.1 Linear Incremental Hydraulic Actuators . . . . . . . . . . 9

2.1 .1 Skidding System . . . . . . . . . . . . . . 9

2.1 .2 Strand Jack . . . . . . . . . . . . . . . . . . . . . . 10

2.2 The Basic Concept - The Inchworm Motor . . . . . . . . . 12

2.3 Hydraulic Actuation . . . . . . . . . . . . . . . . 12

3 The System 15

3.1 The System in Consideration _. . . . . . . . . . . 15

3.2 The System Model . . . . . . . . . . . . . . . . . . . . . . . . . 19

3.2.1 The Engaging / Disengaging Subsystem . . . . . . . . 19

3.2.1.1 The Clamping Element . . . . . . . . . . . 20

3.2.1.2 The Actuation System . . . . . . . . . . . . 22

3.2.1.3 Results . . . . . . . . . . . . . . . 22

3.2 .1 .4 Slip . . . . . . . . . . . . . . . 22

3.2 .2 Load Subsystem . . . . . . . . . . . . . . . . . . . . 23

3.2 .3 Equations of Motion . . . . . . . . . . . . . . 24 
3.2.3.1 Cylinder Disengaged . . . . . . . . . . . . . 24

3.2.3.2 Load while both Cylinders Disengaged . . . . 25

3.2.3.3 One Cylinder Engaged . . . . . . . . . . . . . . . . 25

3.2.3.4 Both Cylinders Engaged . . . . . . . . . . . . . . . . . 25

3.2 .4 Cylinder Valve Subsystem . . . . . . . . . . . . . . . . . . . . . . . . 26

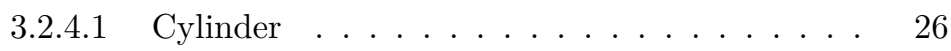

3.2.4.2 Proportional Valve . . . . . . . . . . . . . . . . . . . . . . . . 26

3.2.4.3 Reduced System . . . . . . . . . . . . . 27

4 The Gaits $\quad 29$

4.1 Gait: Free Motion . . . . . . . . . . . . . . . 30

4.2 Gait: Short Stroke or Hold . . . . . . . . . . . . . 30

4.3 Gait: Short Stroke, Accumulated Force . . . . . . . . . . . 31

4.4 Gait: Infinite Hydraulic Stiffness . . . . . . . . . . . . . 31

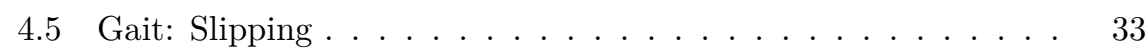

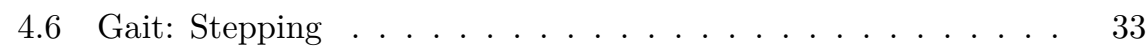

4.7 Gait: Stepping Simplified . . . . . . . . . . . . . 34

4.8 Gait: Smooth Motion . . . . . . . . . . . . . . . 35

4.9 Gait: Ballistic Gait . . . . . . . . . . . . . . . . . . . . . . . . . . . . . . . .

4.10 Combining Gaits . . . . . . . . . . . . . 40

5 Discussion $\quad 41$

5.1 Feasibility of the Mechanical Subsystem . . . . . . . . . . 41

5.2 Feasibility of the Hydraulic Subsystem . . . . . . . . . . . 42

5.3 Feasibility of the Control Subsystem . . . . . . . . . . 43

5.4 Characteristics . . . . . . . . . . . . . . . . 44

5.5 Control Concept for the Gait Smooth Motion . . . . . . . 45

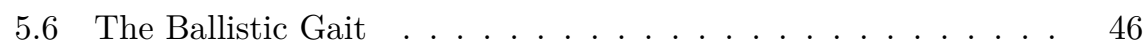

6 Conclusion 49

$\begin{array}{ll}\text { Appendix } & 53\end{array}$

$\begin{array}{ll}\text { Notation } & 53\end{array}$ 
$\begin{array}{ll}\text { Bibliography } & 63\end{array}$

Appended Papers . . . . . . . . . . . . . . . . 70

Not Appended Papers . . . . . . . . . . . . . . . . 71

$\begin{array}{ll}\text { Appended Papers } & 75\end{array}$

I IEEE 2017 - Tracking Control for High Performance Motion of an Hydraulic Infinite Linear Actuator

II SICFP 2017 - Hydraulic Infinite Linear Actuator - The Ballistic Gait - Digital Hydro-Mechanical Motion

III FPNI 2016 - Motion Control Concepts for the Hydraulic Infinite Linear Actuator

IV IFK 2016 - The Hydraulic Infinite Linear Actuator - properties relevant for control 


\section{Introduction}

Linear incremental hydraulic actuator, the systems in consideration in this thesis, combine one or more short-stroke actuators, cylinders, and two or more engaging/disengaging mechanisms into one actuator with long, medium, or even unlimited stroke length. The motion of each single short-stroke actuator concatenated by the engaging/disengaging mechanisms forms the motion of the linear incremental hydraulic actuator.

The patterns of how these motions are concatenated form the gaits of a specific linear incremental hydraulic actuator, see Chapter 4. Linear incremental hydraulic actuators may have more than one gait. In an application, the gaits may be combined to achieve optimal performance at various operating points.

The distinguishing characteristic of linear incremental hydraulic actuators is the incremental motion. The term incremental actuator is seen as analogous to the incremental versus absolute position sensor. Incremental actuators realize naturally relative positioning.

Incremental actuators may realize discrete incremental or continuous incremental motion. Discrete incremental actuators can only approach discrete positions, whereby stepper drives [Sil15] are one prominent example. In contrast, continuous incremental actuators may approach any position. Linear electric motors are one example of continuous incremental actuators.

The actuator has no inherent limitation in stroke length, as every step or cycle adds only to the state at the beginning of the step or cycle and does not depend on the absolute position. This led to the alternative working title Hydraulic Infinite Linear Actuator. This alternative working title points out one possible consequence of incremental actuation. The title chosen for this dissertation, linear incremental hydraulic actuator, addresses the working principle.

In this thesis, the term conventional hydraulic actuator is used for conventional hydraulic drives, for example hydraulic servo drives [Mer67; JK04; Wat09; 
Ryd16], to distinguish between the hydraulic cylinders used as a component in the linear incremental hydraulic actuator and the conventional hydraulic actuator as a whole actuator.

\subsection{Background / Motivation}

This thesis investigates one class of actuators for high-power linear motion, able to provide long, or even unlimited stroke. A prominent actuator for high-power linear motion is the conventional hydraulic actuator. Conventional hydraulic actuators commonly consist of conventional hydraulic cylinders, see Figure 1.1, and a valve system. Conventional hydraulic actuators are often used to actuate pivot motion, rotation, such as in the arm of an excavator. This pivot motion is not the focus of this thesis, although it is not explicitly excluded. Examples of machines using conventional hydraulic actuators for linear motion include many kinds of presses, injection molding machines, press brakes (bending sheet metal), and feeding in for example in drilling rigs. A variant of conventional hydraulic cylinders, telescope cylinders, is used for example in hydraulic elevators.

The major limitations in realizing long linear motion with conventional hydraulic cylinders are buckling, hydraulic stiffness, hydraulic capacitance, integration, production, and assembly.

Hydraulic stiffness and hydraulic capacitance affect the dynamic behavior of the overall system negatively and make it more difficult to control with increasing stroke length. The influence of stroke length on dynamic behavior and thus hydraulic stiffness and natural frequency [Wat09; Mer67; JK04; Vie80; Ryd16] are usually compensated for by decreasing the system pressure. Decreasing the system pressure results in increased component dimensions and oil volumes. The increased component dimensions, especially the increased rod diameter, also reduce the buckling risk for a given stroke length.

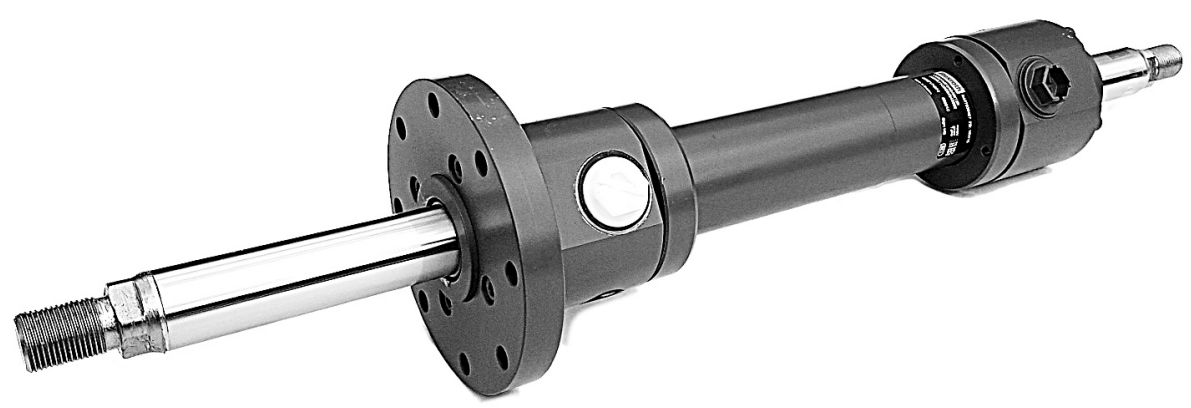

Figure 1.1 Symmetrical, double-acting, conventional hydraulic cylinder 
In the case of differential, plunger and telescope cylinders change the total oil volume in the cylinder with cylinder position. The tank thus has to be dimensioned accordingly, which leads to big tanks containing huge amounts of oil.

Also for long-stroke linear actuation, minimal material usages and minimal oil volumes, and therefore high system pressure are required for economic and environmental reasons. This cannot be achieved with conventional hydraulic cylinders. Linear incremental hydraulic actuators can be a practical concept for overcoming these limitations.

Aiming for performance, medium stroke length linear actuators may also benefit from the same advantages, as there are high hydraulic stiffness and low hydraulic capacitance.

The concept has also emerging properties, like the option to double the force for short strokes, see Section 4.3, which may be beneficial in some applications.

Today only simple variants of linear incremental hydraulic actuators are used and only in niches like in the examples presented in Section 2.1. One explanation why linear incremental hydraulic actuators are not commonly used may be the high complexity and high necessary control effort compared to conventional hydraulic actuators. Another cause may be the lack of necessary components like suitable engaging/disengaging mechanisms or valves.

The concept has the potential to

- decrease the necessary resource usage,

- minimize environmental impact, e.g. from potential oil spillage,

- extend the range of feasible products,

- provide an agile component [Dov14]

- and may simplify integration

in at least some applications. 


\subsection{Aim}

The central goal in mind is a market-ready product "linear incremental hydraulic actuator". This goal reaches far beyond this thesis. Therefore, the aim of the thesis is to investigate the potential of linear incremental hydraulic actuators with the focus on motion control aspects. The delivered artifacts are intended to support future development of such actuators.

\subsubsection{Research Questions}

From the aim, the following research questions and their rationale have been derived.

\section{RQ1}

What are the characteristics of a linear incremental hydraulic actuator?

To be interesting, a new kind of actuator has to come with new or improved characteristics while at least partially maintaining the performance of conventional actuators. Therefore, on a general level, without a detail design of the actuator, linear incremental hydraulic actuators need to be investigated.

RQ2

How can smooth, comparable to a conventional hydraulic servosystem, motion be realized?

To replace conventional hydraulic servo-systems is a likely and attractive generic application of linear incremental hydraulic actuators. Linear incremental hydraulic actuators are more complex and switching the load between multiple cylinders may introduce unacceptable jerk into the system. This may be a knock-out criterion in many applications.

RQ3

How can the additional freedom be used beneficially?

The linear incremental hydraulic actuators used for most investigations in this thesis have three mechanical degrees of freedom (DoFs), two continuous and two discrete control inputs. Other variants of the linear incremental hydraulic actuator may have even more or also fewer DoFs and control inputs. A conventional hydraulic cylinder actuator on the other hand has one mechanical DoF and one continuous control input. 


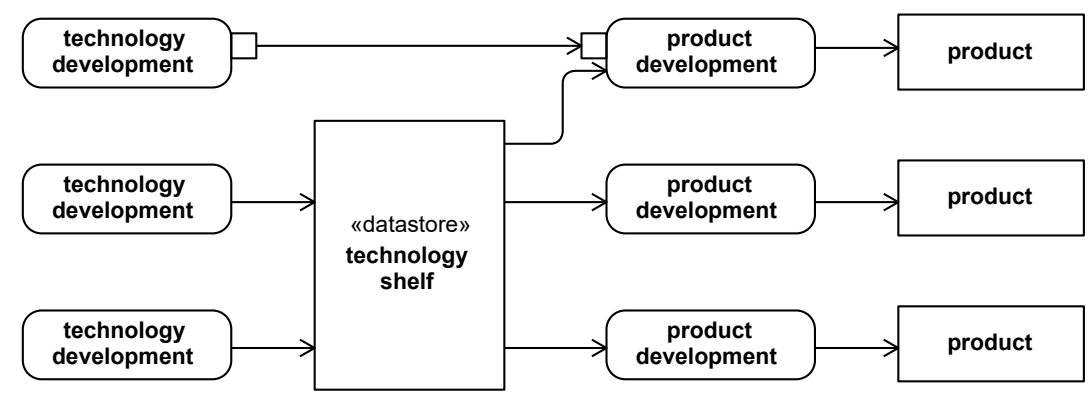

Figure 1.2 Technology Development / Product Development, see [Rei97]

\subsection{Scope}

The starting situation for this work was a given idea or basic concept, see [5], later characterized as the linear incremental hydraulic actuator.

Therefore, this was not a market-pull situation where solutions for a given problem are investigated but more a technology-push situation [UE12; Rei97]. In technology-push, a technology is given and potential products incorporating the technology, and thus the problems to solve, are investigated, Figure 1.2. This work goes one step further and investigates parts of a technology intended for technology-push and thus takes part in technology development. This research is intended to deliver some of the groundwork needed to potentially following technology development and development of products employing linear incremental hydraulic actuators.

As the problems to solve and requirements of any potential product are not known, investigation of the type "Can a linear incremental hydraulic actuator be used in product X?" cannot be made. This research therefore investigates basic properties and potential operation modes, the gaits, and their potential performance.

To continue to pursue a technology, the technology and thus its parts and aspects have to be feasible to a certain degree. In this work, many high-risk parts and aspects have been initially investigated to ensure a certain degree of feasibility. To go further, the following assumptions have been made and the necessary work postponed.

- Proper engaging/disengaging mechanisms exist or will be possible to develop. Promising candidates are known but require further investigation. Critical topics: Tribology, durability, response, energy consumption, state when de-energized, and more.

- Proper compact mechanical designs will be possible. For this research, a 


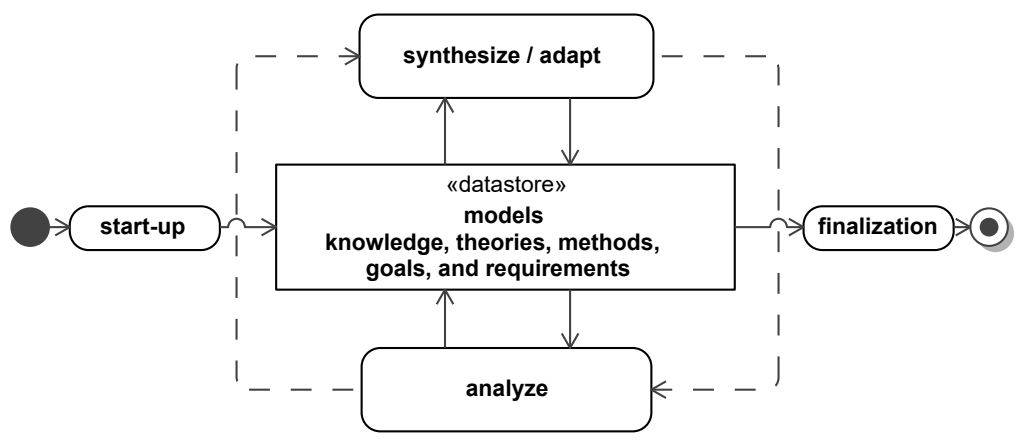

Figure 1.3 Iteration, time aspect.

linear incremental hydraulic actuator has been designed and dimensioned but the ambition was that this design can be realized with reasonable effort for initial testing with focus on motion control in a lab environment. Critical topics: buckling, alignment, and more.

- A sufficiently energy-efficient solution can be found.

- A sufficiently safe and reliable solution can be found.

- Solution affordable for some markets can be found.

\subsection{Research Method}

For the presented research, a method similar to commonly used modern Mechatronics R\&D methods was used. The development is performed mainly in the virtual world by developing various models, for example simulation models, and other virtual artifacts, like dimensioning algorithms and CAD models. Additionally, the development is supported by real-world experiments, where necessary.

Progress is made by an iterative sequence of synthesis / adaptations and analyses, see Figure 1.3. This sequence can also be interpreted as a sequence of proposing a hypothesis with a following falsification. This loop was applied on various hierarchical levels. In some cases the steps in these iterations are time-consuming and in others they blend into each other.

According to Ulrich and Eppinger [UE12], a prototype can be classified according to how physical or analytical it is and according to the scope. The scope can be focused, e.g. when investigating a component or effect, or comprehensive when investigating the whole product in its designated environment. Ulrich 


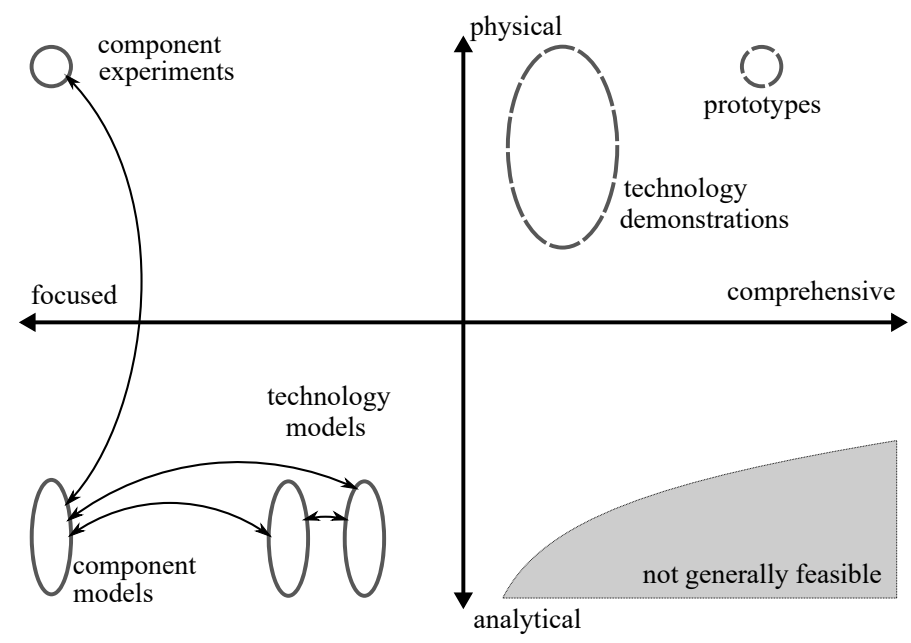

Figure 1.4 Experiment / model classification following Ulrich and Eppinger [UE12]. The area of the blobs symbolizes where in this diagram the experiments / models may fit. The arrows show how the experiments / models influence each other.

and Eppinger use the term prototype as synonym for model, test, experiment, simulation, and other terms.

Figure 1.4 shows the situation in this thesis. The main contributions are related to the technology models. Component models and other details are required as building blocks. These component models are based on existing knowledge from trustworthy publications, virtual and real-world experiments, and dialogs with experts. Product-near prototypes or conclusive technology demonstrations are not in the scope of this thesis.

Building and performing real-world experiments is resource-consuming. Clausing [Cla94] introduces hardware swamp as a risk in product development which is also relevant in research. "Hardware swamps occur when the prototype iterations are so numerous and so overlapping in time that the entire team becomes swamped by the chores of debugging and maintaining experimental hardware."

Virtual experiments often require less resources and have also other advantages like reproducibility and the ability to be stored.

Similar to Figure 1.3, Suh [Suh90] describes the design process as a feedback control loop, Figure 1.5, where $u$ is the input or problem definition, $y$ the output or solution, $G$ the synthesis capability, and $H$ the analysis capability. This feedback control loop can be formulated as a transfer function as follows.

$$
\frac{y}{u}=\frac{G}{1+G H} \approx \frac{G}{G H}=H^{-1} \quad \text { for } \quad G H \gg 1
$$




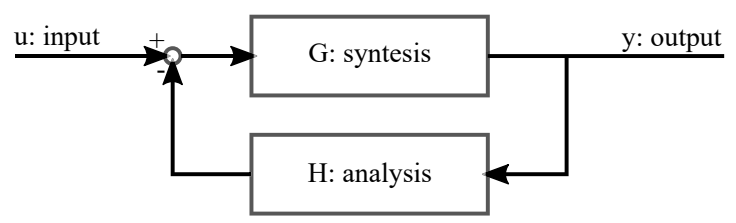

Figure 1.5 Suh's [Suh90] feedback control loop depicting the design process.

Suh states that the loop gain $G H$ should be as large as possible so that the design process converges to the correct solution quickly. For a large loop gain, the transfer function becomes the inverse of the analysis capability $H$ and is therefor independent of the synthesis capability. Interesting here is also the similarity to numerical iterative approximation methods to solve an inversion problem and to Figure 1.3.

This thesis focuses on motion control and the produced artifacts are mainly lumped element simulation models, mathematical models, control algorithms, design algorithms, and analysis and presentation programs. As all these artifacts are actually software, a method similar to a known software development method, test-driven development (TDD), can be applied.

In short, TDD [Gre11] can be described as follows. The developer turns requirements into test cases. Test cases are itself programs, that test the requested functionality. Then, the software is improved to pass the new and all existing test cases. The next step is refactoring, where the developer cleans up and reorganizes the existing code. These steps are repeated to add more and more functionality in small increments. The growing set of test cases ensures that existing functionality does not break undetected. The key in TDD is test automation, so that a large number of test cases can be reliably and conveniently executed. For software development, sophisticated tools exist to support TDD.

In the case of the development of mechatronic products, the support for such a development method is still limited in common tools. Nevertheless, the basic method is commonly used substituting missing tool support with manual work and engineering skills. 


\section{2 \\ State of the Art}

\subsection{Linear Incremental Hydraulic Actuators}

Linear incremental hydraulic actuators are commonly unknown and are not an intensively researched class of actuators. However, the concept is not new. There exist patents describing the principle of the linear incremental hydraulic actuator from the years 1978 [RB78] and 1985 [HI85]. The German book "Autonome Produktionszellen" [PS05] from the year 2005 presents the same principle as the "hydraulischer Schrittmotor" (hydraulic stepper drive). No scientific article has been found even though it is unlikely that the principle is not investigated in for example articles about unfamiliar specific applications.

Two examples of commercial products utilizing concepts similar to the linear incremental hydraulic actuator are Strand Jacks and Skidding Systems.

\subsubsection{Skidding System}

Skidding systems, like the ones from ENERPAC [EpSS] Heavy Lifting Technology, see Figure 2.1, and Bosch Rexroth [BRSS], are used to move huge loads horizontally in temporary or permanent installations. These systems are for example used in the construction industry to move parts of bridges, in plant construction to move transformers, and in offshore applications. They are used in permanent installations like cranes or crossbeams. Skidding systems realize velocities up to $10 \mathrm{~m} / \mathrm{h}$ whereby velocities up to $5 \mathrm{~m} / \mathrm{h}$ are usual.

Skidding systems, like the one shown in Figure 2.1 consist of a skid track, a skid shoe, an anchor block, and a cylinder pair. The anchor block is the engaging/disengaging mechanism which engages on the rail, the rod, integrated into the skid track. The friction between skid track and skid shoe is used as second engaging/disengaging mechanism. The cylinder pair works as one 
cylinder. The anchor block is realized for example by gripper clamps or a claw/notch mechanism.

The skidding system moves the load by extending the cylinder working against the engaged anchor block. After the stroke, the load is held in place by friction or other measures. The cylinder then retracts, moving the disengaged anchor block to the next position. Obviously, there are other realizations of skidding systems possible.

\subsubsection{Strand Jack}

Strand jacks, like the ones from ENERPAC [EpSJ] Heavy Lifting Technology are actuators for heavy lifting applications. Strand jacks pull bundles of strands, steel cables. For example, huge strand jacks pull simultaneously 84 strands with a diameter of $18 \mathrm{~mm}$ to lift $1250 \mathrm{t}$. This system is for example used in the construction industry to lift parts of bridges, and for offshore applications. Strand jacks realize velocities up to $16 \mathrm{~m} / \mathrm{h}$ but usual velocities are much lower.

Strand jacks consist of one main cylinder that provides the lifting stroke. Two anchor systems, the engaging/disengaging mechanisms, realized by a set of wedges, grip each strand separately. The strand bundle corresponds to a rod.

For lifting motion, the lifting cylinder (Main Lifting Jack) extends and the wedges of the top engaging/disengaging mechanism (Top Mini Jack) engage automatically. The pulling of the strands through the bottom engaging/disengaging mechanism leads automatically to its disengagement. When the top position of the lifting cylinder is reached, the lifting cylinder will retract. The reverse of the motion leads automatically to the engagement of the bottom engaging/disengaging mechanism and disengagement of the top engaging/disengaging mechanism. The load stops its motion during retraction.

Lowering is more demanding as the strands are pulled against the automatic locking direction of the wedges through the engaging/disengaging mechanisms. The engaging/disengaging mechanisms therefore have a hydraulically actuated unlocking mechanisms which keeps the engaging/disengaging mechanisms disengaged. Additionally, the load has to be explicitly shifted to the other engaging/disengaging mechanism during each direction change of the lifting cylinder. 


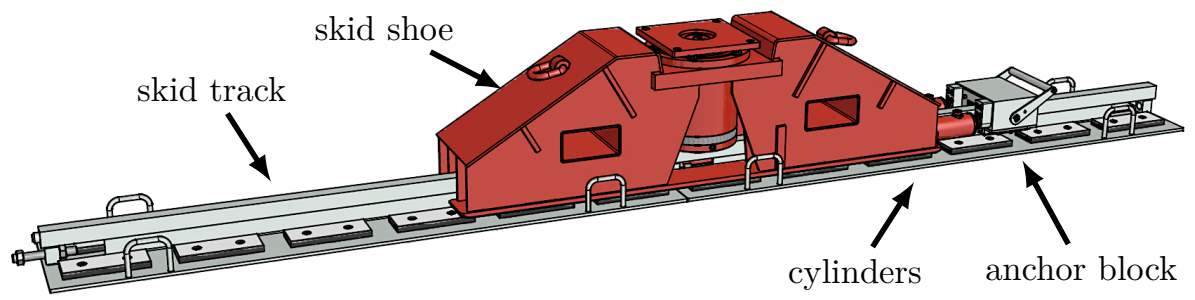

Figure 2.1 Skidding System. Courtesy of ENERPAC [EpSS].

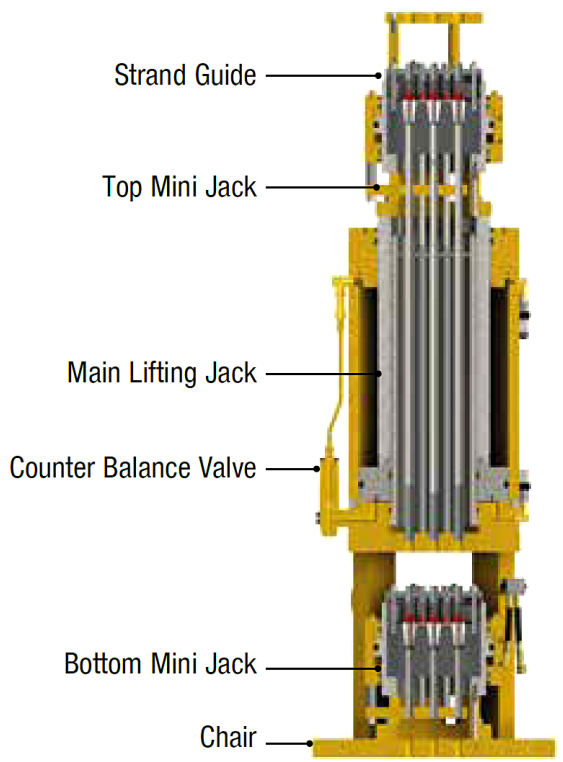

Figure 2.2 Strand Jack. Courtesy of ENERPAC [EpSJ]. 


\subsection{The Basic Concept - The Inchworm Motor}

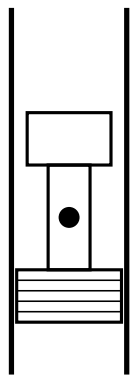

0

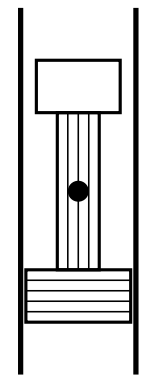

1

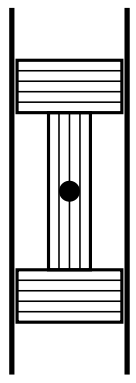

2

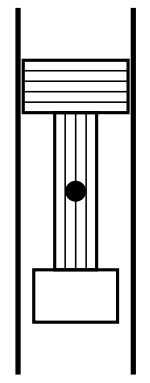

3

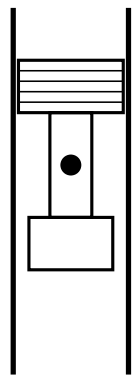

4

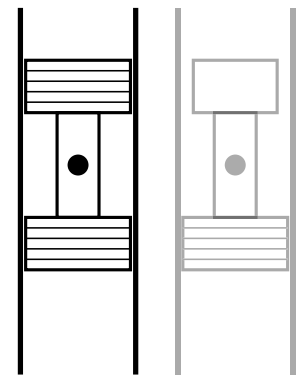

5

Figure 2.3 Inchworm motor motion principle.

The six steps of one motion cycle [WLT13]. White rectangles stand for contracted piezoelectric actuators and hatched rectangles stand for expanded piezoelectric actuators respectively. The black dot symbolizes the mounting point of the load and thus the actuator position. The shaded step 6 is step 0 in the next motion cycle.

Concepts similar to the linear incremental hydraulic actuator exist outside the field of fluid power actuators. One concept is called inchworm motor [WIKIIWM; WLT13]. Other similar concepts are called ultrasonic motor and piezoelectric motor. An inchworm motor uses two piezoelectric actuators for clamping and one for propulsion. The working principle is shown in Figure 2.3. If the load is connected to the middle of the piezoelectric actuator for propulsion, the actuator performs a forward motion in both cases, when expanding and when contracting. This concept has also been realized using other actuators, for example electroactive polymers $[\mathrm{Thu}+16]$.

\subsection{Hydraulic Actuation}

Linear incremental hydraulic actuators are part of the more general class of hydraulic actuators. Other hydraulic actuators are competing technologies. Linear incremental hydraulic actuators are also hydraulic systems in themselves and consist of components for hydraulic actuation.

The area of hydraulic actuation can be divided into linear actuators and rotational actuators. Rotational actuators, also known as hydraulic motors, are commonly realized as positive displacement motors, see for example [II01; Mur98]. Hydraulic motors are usually part of hydro-static transmissions, which are for example used as drivetrains in heavy construction machinery.

The most common linear hydraulic actuator is the conventional hydraulic cylin- 
der, see Figure 1.1. Other, exotic realizations of linear hydraulic actuators are for example hydraulic artificial muscles (HAM) [Tiw+12; Sli17] and their variants.

Conventional hydraulic cylinder actuators can be further categorized by their hydraulic subsystem. Common hydraulic subsystems are on/off hydraulics with directional control valves, hydraulic servo-systems (HSS), digital hydraulics, electro-hydraulic actuators (EHA), and direct driven hydraulic actuators (DDHA).

Electro-hydraulic actuators (EHA), and direct driven hydraulic actuators (DDHA) are integrated solutions of conventional hydraulic cylinders and pumps, whereby the main control input is the pump flow controlled by the shaft speed and/or the pump displacement, see for example [MLP13; MP17; Sou +17$]$.

In the field of electrical drives [Kal12; Sil05; Cet07], the so-called stepper motor allows sensorless positioning. "Sensorless positioning" means in this case that there is no dedicated position sensor used to determine the position of the load but the performed steps are counted to estimate the position. Stepper drives have also been realized by means of pneumatics, see [Sto+07]. Hydraulic stepper drives as investigated in [GPS16; GKS14; GS17; Gra16; PGS16] utilize a valve/piston system delivering a fixed volume of fluid per pulse with high accuracy and thus moving the load a given distance per pulse. The linear incremental hydraulic actuator investigated in this thesis can be operated in gaits realizing sensorless positioning. These are the gaits Stepping, Section 4.6, and Stepping Simplified, Section 4.7.

In this thesis, digital hydraulics [Lin11] is interpreted as an umbrella term for switching hydraulics and secondary control with multi-chamber hydraulic cylinders. Digital pumps are not considered. Digital hydraulics realizes concepts from digital electronics by means of hydraulics.

In switching hydraulics (Linz style digital hydraulics), e.g. [Kog12], fast on/off valves are used to control the flow of fluid exploiting the inductance of the fluid or other system components. The control input is implemented as pulsewidth modulation (PWM) or pulse-frequency modulation (PFM). For example, one switching hydraulic system is the hydraulic buck converter [Kog12]. A linear hydraulic actuator exploiting the inertia of the load in combination with so-called freewheeling valves has been presented in [GS94]. The freewheeling valves allow motion without discharging flow from the supply line.

Another digital hydraulics concept is secondary control with multi-chamber hydraulic cylinders [Lin+09], also called variable displacement linear actuator (VDLA) [HS17]. The enabling components of this concept are cylinders with multiple piston areas. By selecting given pressure levels for each piston area, the effective piston area and thus the actuator's force can be changed. This variability in the effective piston area led to the name variable displacement 
linear actuator.

A hydraulic servo-system (HSS) consists of a symmetrical or differential conventional hydraulic cylinder and a servo valve or proportional valve. In this thesis, the terms servo valve and proportional valve are seen as synonyms, see [Joh12]. The modeling and control of hydraulic servo-systems is extensively treated in common textbooks like [JK04; Mer67; Wat09; Ryd16]. Control of hydraulic servo-systems is still an active research topic, see for example [Koi16; KM17; KM15; And+05; And+15; KSK99; Kug00].

One trend in hydraulic servo-systems is to use valves with independent metering, and another is to use valves with integrated sensors and built-in advanced controllers. An example of valves following both trends is the IndependentMetering Mobile Valve from Eaton [EatonCMA200]. Independent-metering valves can for example be used to improve the control performance [RZ17] or to improve the energy efficiency [KW16]. 


\section{3 \\ The System}

\subsection{The System in Consideration}

The system in consideration in this thesis, the linear incremental hydraulic actuator, is depicted as a Block Definition Diagram (BDD) in Figure 3.2. One possible partial instantiation of the linear incremental hydraulic actuator is shown in Figure 3.1.

As Figure 3.2 shows, linear incremental hydraulic actuators consist of one or more hydraulic cylinders. The piston assembly of each cylinder is equipped with an engaging/disengaging mechanism locking (or unlocking) the cylinder's piston assembly temporarily to the rod. In this work, piston assembly or just piston stands for the whole moving part of the cylinder including all permanently connected parts as there are or may be seals, a rod permanently connected to the piston, and other parts. The term rod is used very generally and includes everything with which the engaging/disengaging mechanism can engage, respectively disengage from. Additionally, there may be an engaging/disengaging mechanism to lock the rod in the actuator.

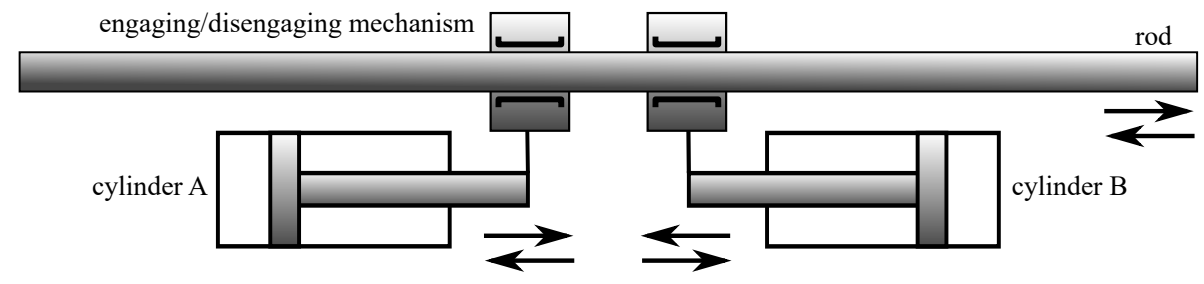

Figure 3.1 Schematic of the system: Two double-acting cylinders temporarily hydraulically detachable from the common rod driving the load. 


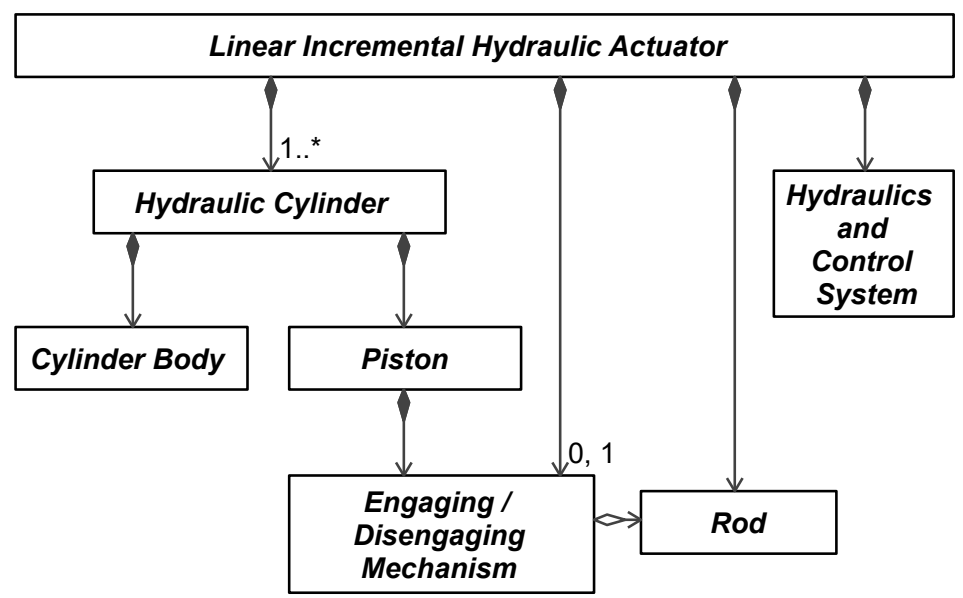

Figure 3.2 SysML Block Definition Diagram [Fri+11; CSM] of the linear incremental hydraulic actuator.

The engaging/disengaging mechanisms may be able to engage at any position, continuous position engagement, or only at defined positions, discrete position engagement, Figure 3.3. An example of a system realizing continuous position engagement is the hydraulic hub-shaft connection [ETPOCT] from ETP Transmission AB [ETP], see Figure 3.8. Discrete position engagement is an interlocking solution featuring for example grooves or cogs. Discrete position engagement mechanisms are realized in industrial applications such as injection molding machines, see Figure 3.4. This work investigates only linear incremental hydraulic actuators with continuous position engagement mechanisms, even though some findings may also apply for discrete position engagement. The hydraulically actuated hub-shaft connection is used as a surrogate for various kinds of continuous position engagement mechanisms.

The engaging/disengaging mechanism may engage automatically, auto-locking, or is controlled by the control system. An example of an auto-locking engaging/disengaging mechanism is one with wedges like in Strand Jacks, see Section 2.1.2, and in Skidding Systems, see Section 2.1.1. An example of a controlled engaging/disengaging mechanism is the hydraulically actuated hubshaft connection from ETP $[\mathrm{ETP}]$, Figure 3.8. This work investigates only linear incremental hydraulic actuators with controlled engaging/disengaging mechanisms.

Another property of engaging/disengaging mechanisms is whether they are engaged, disengaged or undefined when not energized. "Not energized" is the state of the mechanism when no external energy is provided. These states 


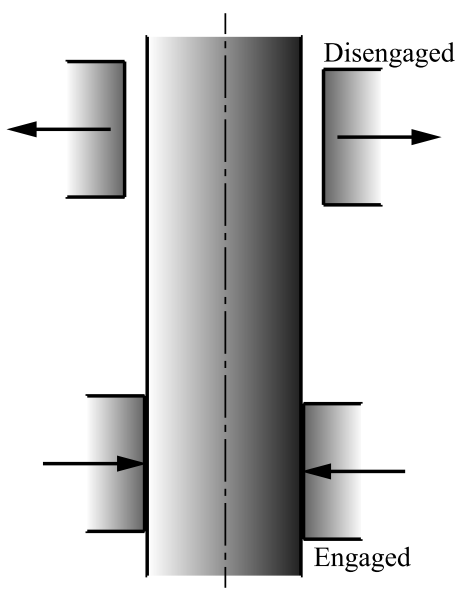

(a) Continuous position engagement

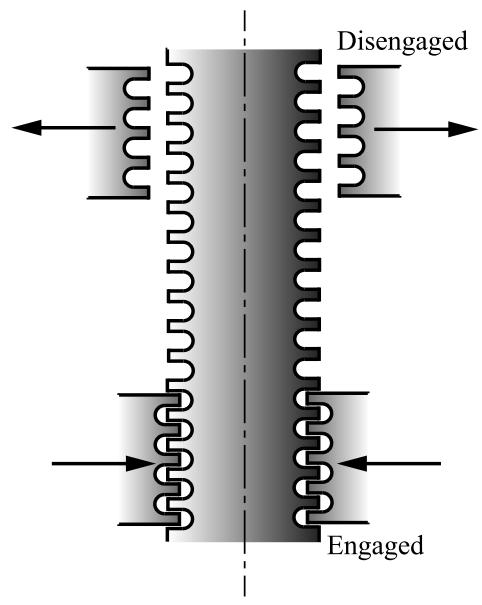

(b) Discrete position engagement

Figure 3.3 Types of engagement.

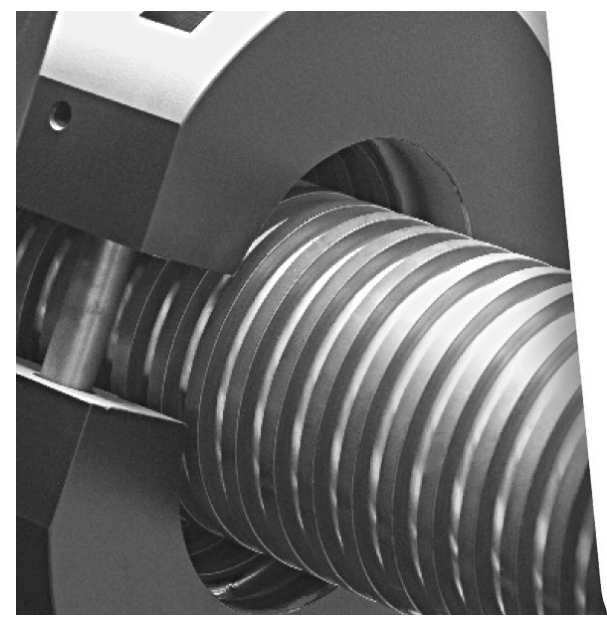

Figure 3.4 Locking mechanism of the clamping unit of an ENGEL DUO injection molding machine. Courtesy of ENGEL [ENGELDUO].

are commonly also called normally-engaged or normally-disengaged, respectively. The hydraulically actuated hub-shaft connection used for investigations engages when pressurized and disengages when the pressure drops. This mechanism is thus disengaged when not energized. Engaging/disengaging mechanisms like the hydraulically actuated clamping and braking element from ZIMMER GROUP [ZIM], see Figure 3.5, need to be pressurized to disengage. This 


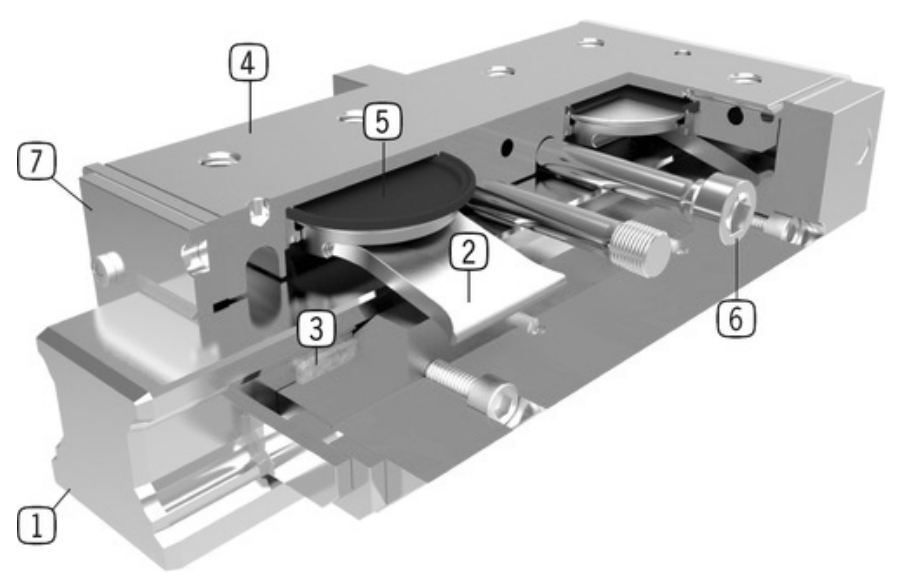

Figure 3.5 Hydraulically actuated clamping and braking element, Series KBHS from ZIMMER GROUP [ZIM].

Energized to open, i.e. engaged when not pressurized, 100000 static clamping cycles, safety element; 1: profile rail from common linear motion guides, 2: knee lever, 3: clamping jaws and brake shoes, 4: housing, 5: membrane, 6: extension bolt 7: scraper. Courtesy of ZIMMER GROUP.

mechanism is thus engaged when not energized.

The actuator can be used so that the load is connected to the rod and the actuator, i.e. the cylinder bodies, is stationary. The opposite case is also possible, where the load is connected to the actuator and the rod is stationary. This work assumes the case where the actuator is stationary, i.e. connected to the inertial frame of reference, and the rod moves, driving the load.

Linear incremental hydraulic actuators possess additional DoFs compared to conventional hydraulic cylinders. These additional DoFs make it possible to operate the linear incremental hydraulic actuators in various gaits. Gaits are the patterns of motion the actuator can operate in. Gaits are discussed in more detail in Chapter 4. 


\subsection{The System Model}

Linear incremental hydraulic actuators as described in Section 3.1 can be realized in various forms. For analysis and especially simulation, it is necessary to specify the system in consideration more concretely. This thesis and the appended papers, see page vii, primarily consider a system like the one investigated in this section and depicted in Figure 3.6. This chapter also provides background information on the system studied in the appended papers, in particular paper [I].

This chapter describes the system, covers mathematical modeling, and presents assumptions made concerning the components. For the purposes of simulation and numerical analysis, a concrete instance of the investigated system is presented. The investigated application lifts a mass, as this is a simple but generic load case, see Section 3.2.2. The investigated linear incremental hydraulic actuator consists of two equal symmetrical cylinders with a continuous position engaging/disengaging mechanism each, see Figure 3.6.

The actuator has three DoFs which are temporarily coupled depending on the discrete states. Hence, the actuator is a hybrid system [Lib03] with both, continuous and discrete states and/or control inputs. The discrete states are formed by the engaging/disengaging states of the engaging/disengaging mechanisms of each cylinder, see Figure 3.7. The on/off valves controlling the engaging/disengaging form the discrete control inputs.

\subsubsection{The Engaging / Disengaging Subsystem}

The engaging/disengaging subsystem is the key subsystem in linear incremental hydraulic actuators and the enabler of the concept. Its purpose is to lock and

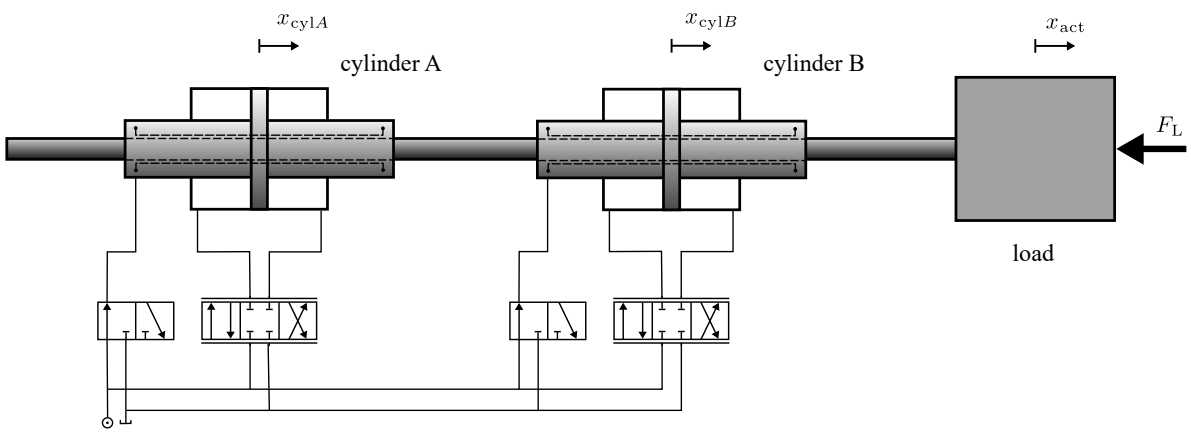

Figure 3.6 Linear incremental hydraulic actuator with two symmetrical cylinders, each actuated by a proportional valve and equipped with a hub-shaft connection as engaging/disengaging mechanism actuated by an on/off valve. 


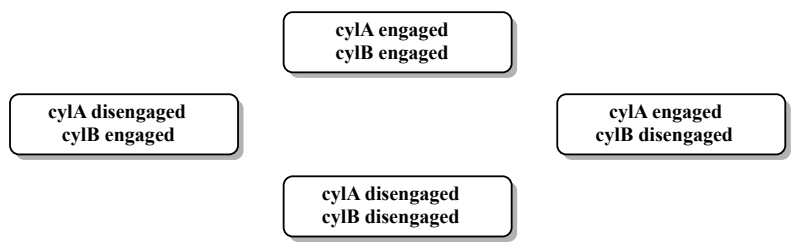

Figure 3.7 Discrete states of the investigated actuator.

unlock the cylinders to the common rod. Safe locking and complete unlocking as well as the timing are critical characteristics.

The control concept proposed in paper [I] assumes only a few characteristics of the engaging/disengaging subsystem as: a) when engaged the transferable force is beyond a specified lower limit; b) when disengaged the disturbance force is below a specified upper limit; c) the engaging process takes less than a specified upper limit of duration $\left.T_{\text {engage }} ; d\right)$ the disengaging process takes less than a specified upper limit duration $T_{\text {disengage }} . T_{\text {engage }}$ and $T_{\text {disengage }}$ consider all delays from the trigger in the software until the required force is actually transferable. This includes for example delays in software, electronics / bus system, valve, pressurization of the clamping element, as well as squeeze and stick effects. They also include the uncertainty in the engaging/disengaging process.

More detailed models could be used to slightly improve the performance of the controller, but that would mean that the controller would depend on effects with limited reproducibility, e.g. friction. For paper [I], the design decision was that the control strategy shall not depend on such effects. The simulation model to test the control strategy considers more details, which are presented in this section.

\subsubsection{The Clamping Element}

In the considered system, the engaging / disengaging is realized with the COTS hydraulically actuated hub-shaft connection Octopus from ETP, [ETPOCT], see Figure 3.8. The hub-shaft connection transfers the cylinder force due to the friction of the hydraulically actuated membrane pressed against the rod.

The friction is modeled as Coulomb friction as follows, see also paper [IV].

$$
F_{\mathrm{c}}= \begin{cases}F_{\mathrm{c} 0} & \text { when: } p_{\mathrm{c}}<p_{\mathrm{c} 0} \\ F_{\mathrm{c} 0}+\mu A_{\mathrm{c}}\left(p_{\mathrm{c}}-p_{\mathrm{c} 0}\right) & \text { else }\end{cases}
$$

$F_{\mathrm{c} 0}$ is the remaining friction force caused for example by scrapers. $p_{\mathrm{c}}$ is the oil pressure in the connection and $p_{\mathrm{c} 0}$ is the minimal pressure where the hub-shaft connection starts to engage. $\mu$ is the friction parameter and $A_{\mathrm{c}}$ the effective area where $p_{\mathrm{c}}$ acts to create the normal force to create the friction force. 


\begin{tabular}{lcr}
\hline valve & \multicolumn{2}{c}{ LCM FSVi 4.1 [FSVi] } \\
switching time & $q_{\text {nom }}$ & $1 \mathrm{~ms}+2 \mathrm{~ms}$ \\
nominal flow at 5 bar & & $5 \mathrm{~L} / \mathrm{min}$ \\
fluid & & $580 \mathrm{cSt}$ \\
kinematic viscosity at $0{ }^{\circ} \mathrm{C}$ & & $144 \mathrm{cSt}$ \\
kinematic viscosity at $20^{\circ} \mathrm{C}$ & & $46 \mathrm{cSt}$ \\
kinematic viscosity at $40^{\circ} \mathrm{C}$ & ETP Octopus $\mathrm{O} 40$ [ETPOCT] \\
clamping element & $p_{\mathrm{c} 0}$ & $1 \mathrm{MPa}$ \\
& $\mu$ & 0.1 \\
friction parameter & & $10 \mathrm{~ms}$ \\
subsystem & $T_{\text {engage }}$ & $10 \mathrm{~ms}$ \\
duration to engage & $T_{\text {disengage }}$ & \\
duration to disengage & & \\
\hline
\end{tabular}

Table 3.1 Parameters for the engaging/disengaging subsystem in simulation.

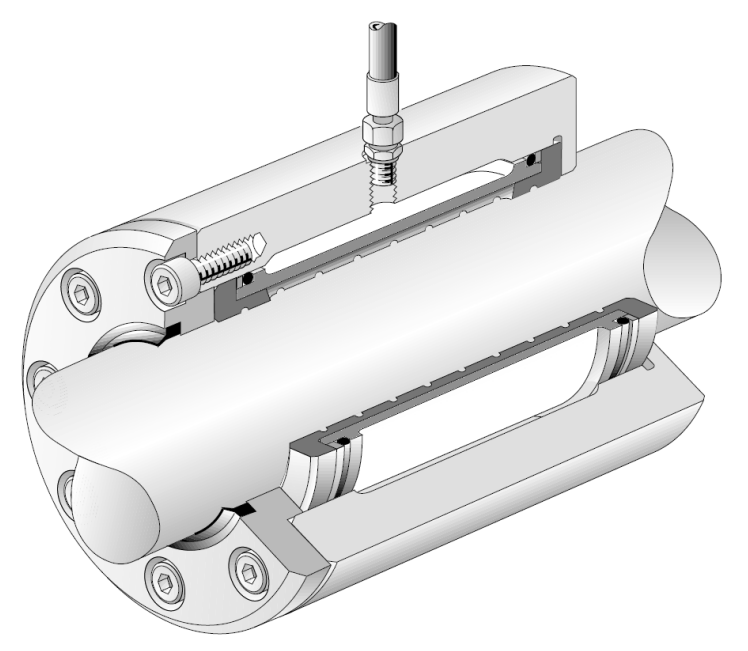

Figure 3.8 Hydraulic hub-shaft connection Octopus [ETPOCT]. Courtesy of ETP Transmission AB [ETP].

Squeeze and stick effects (stiction) between clamp element and rod are assumed to be handled by measures on the hub-shaft connection, for example grooves and surface finish, and are not explicitly modeled. The remaining effect is seen as part of the uncertainty in the pressurization process. It is also assumed that the connection is axially rigid. 


\subsubsection{The Actuation System}

The clamping element is actuated by pressure $p_{\mathrm{c}}$ in the inner volume of the hub-shaft connection, represented as a dark area in Figure 3.8. A fast on/off valve connected to the clamping element via a hose controls the pressurization and depressurization.

The dynamics of the pressurization / depressurization are mainly dependent on the valve dynamics and the pressure build-up and relief in the volume. Hence, accepting the limited fidelity, the actuation system is modeled as volume pressurized through a resistance and a valve. It is assumed that the pressure and tank connection of the valve are supported by accumulators. The volume considers the volume of the hub-shaft connection and the hose. The deformation of both is considered by accordingly increased volumes. The flow resistance in the hose is modeled according to Hagen-Poiseuille [JK04].

Valve The fast switching-valve FSVi 4.1 [FSVi] from Linz Center of Mechatronics $\mathrm{GmbH}$ is used. This valve features a $5 \mathrm{~L} / \mathrm{min}$ at 5 bar pressure drop and a nominal switching time of $3 \mathrm{~ms}$. A summary of the state of the art in digital valve technology can be found in [WPS15].

The opening dynamics of the FSVi are approximated by a delay of $1 \mathrm{~ms}$ and constant acceleration of the poppet, which opens and closes the valve in $2 \mathrm{~ms}$. This simple model fits sufficiently to the plots in the data sheet [FSVi]. Simulation results are shown in Figure 3.9, "valve opening $x_{\mathrm{Vc}}$ ".

\subsubsection{Results}

Figure 3.9 show simulation results of an engaging and a disengaging process. The figure shows that the valve opens and closes within $3 \mathrm{~ms}$.

Within the mentioned assumptions the pressurization / depressurization occurs within $10 \mathrm{~ms}$ at room temperature. At $0{ }^{\circ} \mathrm{C}$ the pressurization still occurs within $10 \mathrm{~ms}$, but in the case of depressurization the friction force is approximately $1.5 \mathrm{kN}$ at $10 \mathrm{~ms}$ and reaches minimum approximately $2 \mathrm{~ms}$ later. In the case of $0{ }^{\circ} \mathrm{C}$, the assumed characteristics thus do not hold.

Assuming the friction parameters specified in the data sheet [ETPOCT], see also Table 3.1, the transferable force reaches approximately $23 \mathrm{kN}$ and exceeds the actuator design force by a factor of 1.15 .

\subsubsection{Slip}

In this contribution, everything resulting in deviation between the actuator position $x_{\text {act }}$ and the accumulated position of the cylinders is named "slip", even 


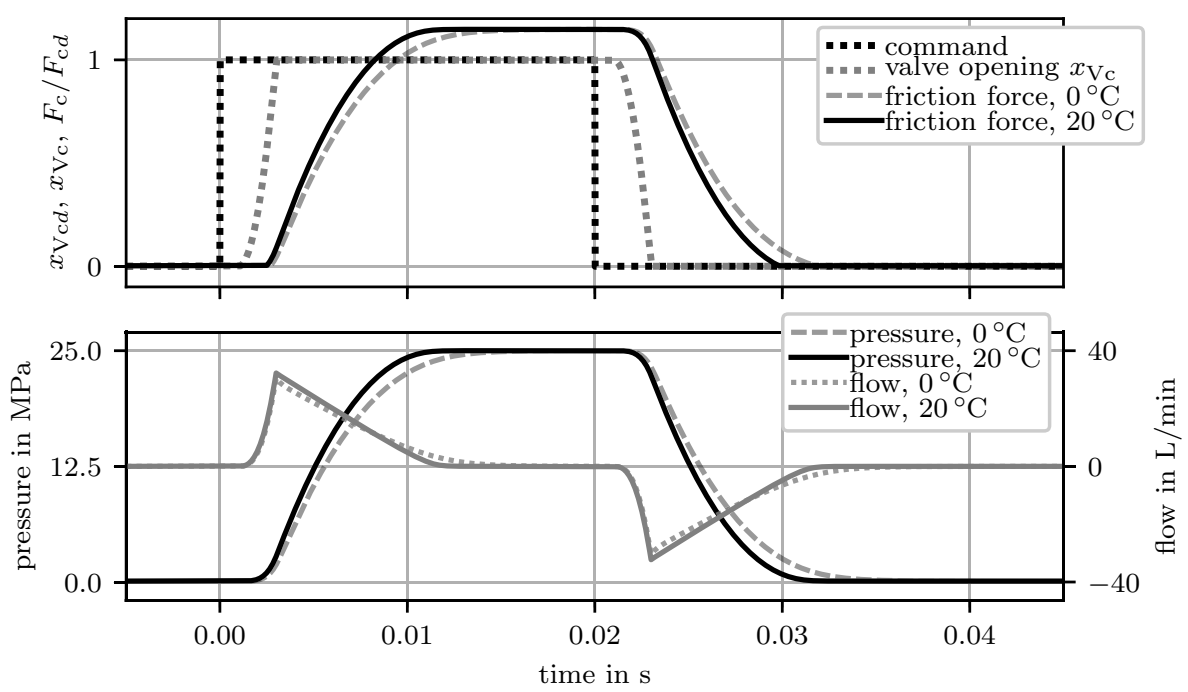

Figure 3.9 Engaging / disengaging subsystem: Simulation results of an engaging and a disengaging process.

though it is not related to sliding under the influence of stiction. The accumulated position is the theoretical actuator position caused by the cylinders if ideal clamping is achieved.

This deviation has many causes and effects. There are a) position accuracy of the cylinders when engaging or disengaging; b) not ideal sensors; c) motion between the reference systems of the sensors, and others. Assuming a Coulomb or Dahl friction model [Wit+95], slip between the pistons and the rod may occur d) while overloaded (force peaks beyond the stiction force); e) while engaging and some period after (fluid, squeeze effect). Slip may also be caused by f) load changes and the elastic deformation of the clamping element and the rod.

Most of these effects cause slip during the engaging and disengaging phase but not during the driving phase. Other effects, like overload, shall not occur in well-dimensioned systems. Slip may also be an integral part of the concept in some systems.

\subsubsection{Load Subsystem}

As discussed, the intention of this contribution is not to design an actuator for one defined application, but, in a technology-push manner [UE12], investigate the properties of this concept to enable decisions as to whether this concept is suitable for emerging applications. 


\begin{tabular}{lcc}
\hline effective load force & $F_{\mathrm{L}}$ & $-20 \mathrm{kN}$ \\
effective mass / inertia & $m_{\mathrm{L}}$ & $2000 \mathrm{~kg}$ \\
effective damping & $b_{\mathrm{L}}$ & $0 \mathrm{Ns} / \mathrm{m}$ \\
\hline
\end{tabular}

Table 3.2 Parameters for the load in simulation.

\begin{tabular}{cclccl}
\hline cyl. A & cyl. B & coupling & $i$ & $j$ & equations \\
\hline $\mathrm{E}$ & $\mathrm{D}$ & {$\left[x_{\text {act }}, x_{\text {cylA }}\right]$} & $\mathrm{A}$ & $\mathrm{B}$ & $3.6+3.2$ \\
$\mathrm{D}$ & $\mathrm{E}$ & {$\left[x_{\text {act }}, x_{\text {cylB }}\right]$} & $\mathrm{B}$ & $\mathrm{A}$ & $3.2+3.6$ \\
$\mathrm{E}$ & $\mathrm{E}$ & {$\left[x_{\text {act }}, x_{\text {cylA }}, x_{\text {cylB }}\right]$} & - & - & 3.7 \\
$\mathrm{D}$ & $\mathrm{D}$ & {[]} & - & - & $3.2+3.2+3.4$ \\
\hline
\end{tabular}

Table 3.3 Equation selection for the four discrete states.

E: engaged, D: disengaged.

Various load cases are discussed in [III]. A load can often be simplified to a (varying) mass with additional force and viscous friction. In this contribution, a case similar to lifting a mass is considered, see Table 3.2. Viscous friction is kept low as this is the worst case scenario.

\subsubsection{Equations of Motion}

The actuator has in total three DoFs. Depending on the discrete states, the DoF of each cylinder can be coupled with the DoF of the load. The DoF of cylinder A or the DoF of cylinder B or the DoFs of both are thus temporarily eliminated.

The equations of motion for the cases Cylinder Disengaged, One Cylinder Engaged and Both Cylinders Engaged are presented in the following. For each discrete state in Figure 3.7 the equations of motion are selected according to Table 3.3.

\subsubsection{Cylinder Disengaged}

Equation 3.2 describes the motion of a disengaged cylinder. Considered are the cylinder force, Equation 3.13, including the friction in the cylinder, Equation 3.14, and the friction between piston and rod, Equation 3.3, see Section 3.2.1.1, Equation 3.1. The friction between piston and rod considers scrapers and guidance. 
This is the case which is relevant during retraction.

$$
\begin{aligned}
\frac{\mathrm{d}^{2}}{\mathrm{~d} t^{2}} x_{\mathrm{cyl} j}= & \frac{1}{m_{\mathrm{P} j}}\left(F_{\text {cyl } j}+F_{\text {d clamp } j}+F_{\text {disturbance }}\right) \\
m_{\mathrm{P} j}= & m_{\mathrm{P} j \text { Steel }}+\rho_{\text {fluid }} V_{A j}\left(x_{\mathrm{cyl} j}\right)+\rho_{\text {fluid }} V_{B j}\left(x_{\mathrm{cyl} j}\right) \\
F_{\mathrm{d} \text { clamp } j}= & -b_{\text {clamp }} \frac{\mathrm{d}}{\mathrm{d} t}\left(x_{\mathrm{cyl} j}-x_{\mathrm{act}}\right) \\
& -\operatorname{sign}\left(\frac{\mathrm{d}}{\mathrm{d} t}\left(x_{\mathrm{cyl} j}-x_{\mathrm{act}}\right)\right) F_{\text {coulomb }, \text { clamp }}
\end{aligned}
$$

\subsubsection{Load while both Cylinders Disengaged}

This case describes the motion of the load when both cylinders are disengaged. It considers the load force and load friction as well as the friction between pistons and rod.

$$
\begin{aligned}
\frac{\mathrm{d}^{2}}{\mathrm{~d} t^{2}} x_{\mathrm{act}} & =\frac{1}{m_{\mathrm{L}}}\left(F_{\mathrm{L}}+F_{\mathrm{fL}}-F_{\mathrm{d} \operatorname{clamp} A}-F_{\mathrm{d} \operatorname{clamp} B}\right) \\
F_{f L} & =-b_{\mathrm{L}} \frac{\mathrm{d}}{\mathrm{d} t} x_{\mathrm{act}}
\end{aligned}
$$

\subsubsection{One Cylinder Engaged}

In this case one cylinder, cylinder $i$, is engaged with the load while the other, cylinder $j$, is disengaged

$$
\begin{aligned}
\frac{\mathrm{d}^{2}}{\mathrm{~d} t^{2}} x_{\mathrm{act}} & =\frac{1}{m}\left(F_{\mathrm{cyl} i}-F_{\mathrm{d} \operatorname{clamp} j}+F_{\mathrm{L}}+F_{\mathrm{fL}}\right) \\
m & =m_{\mathrm{P} i}+m_{\mathrm{L}}
\end{aligned}
$$

\subsubsection{Both Cylinders Engaged}

In this case both cylinders are engaged with the load.

$$
\begin{aligned}
\frac{\mathrm{d}^{2}}{\mathrm{~d} t^{2}} x_{\mathrm{act}} & =\frac{1}{m}\left(F_{\text {cylA }}+F_{\text {cylB }}+F_{\mathrm{L}}+F_{\mathrm{fL}}\right) \\
m & =m_{\mathrm{PA}}+m_{\mathrm{PB}}+m_{\mathrm{L}}
\end{aligned}
$$




\subsubsection{Cylinder Valve Subsystem}

The derivation of the equations for a system like that in Figure 3.6 can be found in various textbooks, for example [JK04] and [Wat09]. See also [Kug00]. They are included here for consistency and completeness.

\subsubsection{Cylinder}

$$
\begin{aligned}
F_{\mathrm{h}} & =A_{\mathrm{PA}} p_{\mathrm{A}}-A_{\mathrm{PB}} p_{\mathrm{B}} \\
\frac{\mathrm{d}}{\mathrm{d} t} p_{\mathrm{A}} & =\frac{E}{V_{A}\left(x_{\mathrm{P}}\right)}\left(q_{\mathrm{A}}-A_{\mathrm{PA}} \frac{\mathrm{d}}{\mathrm{d} t} x_{\mathrm{P}}\right) \\
\frac{\mathrm{d}}{\mathrm{d} t} p_{\mathrm{B}} & =\frac{E}{V_{B}\left(x_{\mathrm{P}}\right)}\left(q_{\mathrm{B}}+A_{\mathrm{PB}} \frac{\mathrm{d}}{\mathrm{d} t} x_{\mathrm{P}}\right) \\
V_{\mathrm{A}}\left(x_{\mathrm{P}}\right) & =V_{0 \mathrm{~A}}+A_{\mathrm{PA}} x_{\mathrm{P}} \\
V_{\mathrm{B}}\left(x_{\mathrm{P}}\right) & =V_{0 \mathrm{~B}}-A_{\mathrm{PB}} x_{\mathrm{P}}
\end{aligned}
$$

The cylinder friction, $F_{\mathrm{f} \text { cyl }}$, is modeled as viscous and Coulomb friction.

$$
\begin{aligned}
F_{\text {cyl }} & =F_{\mathrm{h}}+F_{\mathrm{f} \text { cyl }} \\
F_{\mathrm{f} \text { cyl }} & =-b_{\text {cyl }} \frac{\mathrm{d}}{\mathrm{d} t} x_{\mathrm{P}}-\operatorname{sign}\left(\frac{\mathrm{d}}{\mathrm{d} t} x_{\mathrm{P}}\right) F_{\text {coulomb }, \text { cyl }}
\end{aligned}
$$

Table 3.4 shows the parameters used in simulation. Friction in cylinders is pressure-dependent. In the used simulation models this pressure dependence is ignored. For the case Cylinder Disengaged the cylinder friction force is a dominating part of the load. In this case the chamber pressures are always near to $\frac{p_{\mathrm{S}}+p_{\mathrm{T}}}{2}$ and thus the pressure dependence has little influence if parameters are selected for this working point. In the case when driving the load, load forces are dominant and the cylinder friction has less influence and the pressure dependence is considered as disturbance. More complex models like Stribeck, LuGre, Dahl [Wit+95] are not applied. The friction parameters are estimated from measurement results in [Amo16]. The parameters are scaled proportionally according to the sum of the lengths of the seal's edges.

\subsubsection{Proportional Valve}

The valve is assumed to be of a fast servo valve kind with linear characteristics. Under-lapped characteristics are considered in the simulation model and controller design but not presented in this work for readability reasons.

The dynamics of the valve are modeled as a combination of a rate limitation 


\begin{tabular}{lrr}
\hline type & & symmetrical \\
piston area & $A_{\mathrm{P} i j}$ & $1180 \mathrm{~mm}^{2}$ \\
stroke & & $\pm 100 \mathrm{~mm}$ \\
chamber volume at $x_{\mathrm{cyl}}=0 \mathrm{~m}$ & $V_{0 i j}$ & $300 \mathrm{~cm}^{3}$ \\
piston mass & $m_{\mathrm{P} j}$ & $18 \mathrm{~kg}$ \\
viscous friction coefficient & $b_{\mathrm{cyl} j}$ & $1000 \mathrm{~N} \mathrm{~s} / \mathrm{m}$ \\
coulomb friction & & $300 \mathrm{~N}$ \\
\hline
\end{tabular}

Table 3.4 Parameters for the cylinders in simulation.

\begin{tabular}{lcr}
\hline nominal flow at 35 bar per edge & $q_{\text {nom }}$ & $25 \mathrm{~L} / \mathrm{min}$ \\
corner frequency for small amplitudes & $f_{\mathrm{V}}$ & $200 \mathrm{~Hz}$ \\
damping & $\delta$ & 0.7 \\
actuating time for signal step 0 to 1 & $T_{\mathrm{V} \text { step }}$ & $5 \mathrm{~ms}$ \\
\hline
\end{tabular}

Table 3.5 Parameters for the proportional valve in simulation.

that considers a limited spool velocity and a PT2 element.

$$
\begin{aligned}
q_{A}= & c_{V A S} \operatorname{sg}\left(x_{V}\right) \sqrt[1]{p_{S}-p_{A}} \\
& -c_{V A T} \operatorname{sg}\left(-x_{V}\right) \sqrt[1]{p_{A}-p_{T}} \\
q_{B}= & c_{V B S} \operatorname{sg}\left(-x_{V}\right) \hat{\sqrt{p_{S}-p_{B}}} \\
& -c_{V B T} \operatorname{sg}\left(x_{V}\right) \sqrt[\hat{p}]{p_{B}-p_{T}} \\
\frac{\mathrm{d}^{2}}{\mathrm{~d} t^{2}} x_{V}= & \omega_{\mathrm{V}}^{2}\left(u-\frac{2 d}{\omega_{\mathrm{V}}} \frac{\mathrm{d}}{\mathrm{d} t} x_{V}-x_{V}\right) \\
\left|\frac{\mathrm{d}}{\mathrm{d} t} x_{V}\right|<= & \dot{x}_{V \text { limit }} \approx \frac{1}{T_{\text {V step }}}
\end{aligned}
$$

To simplify the way of writing the equations the following shortcuts are used.

$$
\begin{aligned}
\operatorname{sg}(u) & = \begin{cases}0 & \text { for } u<0 \\
u & \text { else }\end{cases} \\
\sqrt{u} & =\operatorname{sign}(u) \sqrt{|u|}
\end{aligned}
$$

For the simulation, parameters similar to the high-response directional control valve BOSCH 4WRREH6-25L are used, see Table 3.5. The valve is assumed to be without hysteresis.

\subsubsection{Reduced System}

For the controller design, a reduced model is derived by introducing load pressure $p_{\mathrm{L}}=p_{\mathrm{A}}-p_{\mathrm{B}}$ according to [JK04]. With the symmetry assump- 
tions $\frac{p_{\mathrm{S}}+p_{\mathrm{T}}}{2}=\frac{p_{\mathrm{A}}+p_{\mathrm{B}}}{2}$ and the simplifications $V=V_{\mathrm{A}}=V_{\mathrm{B}}=V_{\mathrm{A} 0}=V_{\mathrm{B} 0}$, $E=E_{\mathrm{A}}=E_{\mathrm{B}}$, follows

$$
\begin{aligned}
q_{\mathrm{L}} & =c_{\mathrm{V}} x_{\mathrm{V}} \frac{1}{\sqrt{2}} \sqrt{p_{\mathrm{S}}-p_{\mathrm{T}}-\operatorname{sign}\left(x_{\mathrm{V}}\right) p_{\mathrm{L}}} \\
\frac{\mathrm{d}}{\mathrm{d} t} p_{\mathrm{L}} & =\frac{E}{V}\left(2 q_{\mathrm{L}}-2 A_{\mathrm{P}} \frac{\mathrm{d}}{\mathrm{d} t} x_{\mathrm{P}}\right) \\
q_{\mathrm{L}} & =\frac{q_{\mathrm{A}}-q_{\mathrm{B}}}{2}=q_{\mathrm{A}}=-q_{\mathrm{B}}
\end{aligned}
$$




\section{4}

\section{The Gaits}

The motions of the cylinders are concatenated by engaging and disengaging to the motion of the actuator. The patterns of how the cylinders are concatenated form the gaits. The gaits are therefore the principal categories of how to control the motion of a linear incremental hydraulic actuators.

Which gaits can be realized in a proper way is determined by the design of the actuator. Relevant are for example the number of cylinders, the engaging/disengaging mechanisms, sensors, and the hydraulic subsystem, especially the valves. Actuators with a higher number of cylinders and engaging/disengaging mechanisms, and therefore a higher number of DoFs, may realize a higher number of distinct gaits.

An application may use exclusively one gait or it may combine various gaits. Gaits have strengths and weaknesses that may fit various operating points. Combining gaits may thus help to achieve optimal performance over a wide range of operating points. Depending on the application, some gaits may be useful or not.

This chapter outlines gaits which can be realized with an actuator with two equal symmetrical cylinders, see Figure 3.1 and Figure 3.2. The special case where only one cylinder with an engaging/disengaging mechanism is combined with an engaging/disengaging mechanism that locks the actuator to the rod is also considered. The engaging/disengaging mechanism is assumed to be of the continuous position engagement type, see Section 3.1 and Figure 3.3. In this thesis, some gaits have been studied in more detail, others are listed and briefly described.

Each of the two cylinders, A and B, can be engaged or disengaged. This results in four different engagement states for the actuator. The states are shown in Figure 4.1, in the form of a state machine. The pattern of the transitions between these states characterizes a gait. State machines are therefore used in 
this chapter to depict gaits. States, which are not used in a gait, are marked in gray. Some figures show variants of a gait in one graph.

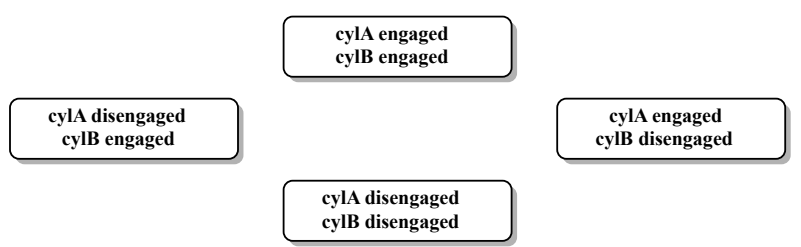

Figure 4.1 State machine: States of the investigated actuator.

\subsection{Gait: Free Motion}

In this gait, all cylinders are disengaged, see Figure 4.2. The actuator affects the load solely with the residual forces of the disengaged cylinders, see Section 3.2.3.2.

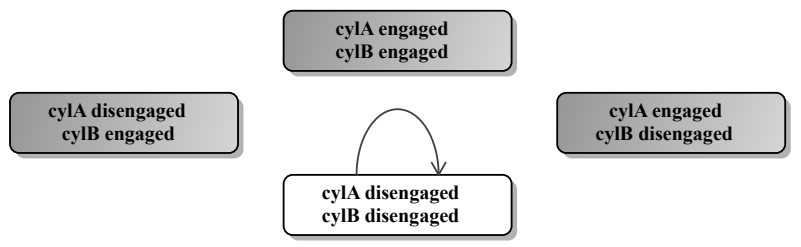

Figure 4.2 State machine: Gait: Free Motion.

This gait may be used in cases where the load is to move freely, e.g. during commissioning or in modes where the load is controlled by other means.

\subsection{Gait: Short Stroke or Hold}

This gait can be realized alternatively in two variants, where cylinder A or where cylinder B is engaged, see Figure 4.3. While the actuator operates in this gait, no engaging or disengaging occurs. In this gait the actuator operates like a conventional hydraulic cylinder with the same stroke length. 

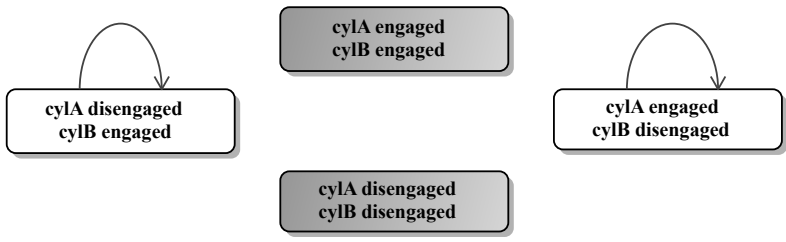

cylB disengage

Figure 4.3 State machine: Gait: Short Stroke or Hold, two variants.

\subsection{Gait: Short Stroke, Accumulated Force}

In this gait both cylinders are permanently engaged, see Figure 4.4. With both

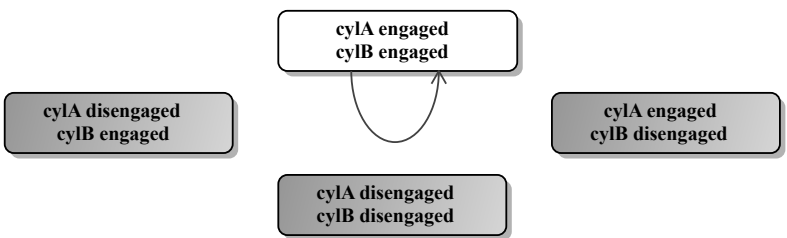

Figure 4.4 State Machine: Gait: Short Stroke, Accumulated Force.

cylinders engaged, twice the force of one cylinder can be applied on the load. This may be relevant in applications where the load has to be move over a longer distance and where one short stroke with higher force is then required. This is an implementation of secondary control.

This gait may also be used to enhance the control performance for a short position interval. Two cylinders driving the load leads to a higher natural frequency. Even though both cylinders are mechanically connected, the hydraulic subsystems are still separated and therefore also the control inputs. The system forms a so-called over-actuated system. This additional freedom may be for example used to increase the system's damping.

\subsection{Gait: Infinite Hydraulic Stiffness}

This gait has been studied in paper [IV].

When the desired position has been reached, one piston disengages and moves to its end-stop while the other holds the load. The position of the load will thus not be changed. Reaching the end-stop, the cylinder chamber opposing the end-stop will be fully pressurized before the cylinder engages. This can then be repeated with the second piston.

After this preparation, the configuration for this gait is set and one or both cylinders are permanently engaged, see Figure 4.5. 


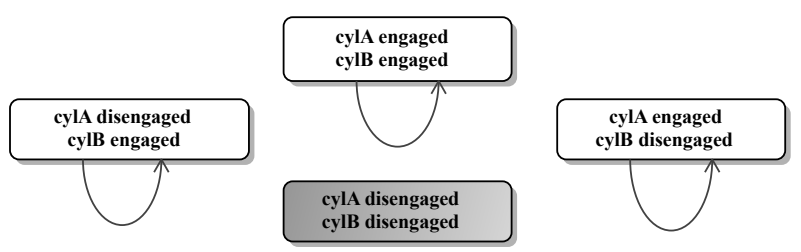

Figure 4.5 State Machine: Gait: Infinite Hydraulic Stiffness, three variants.

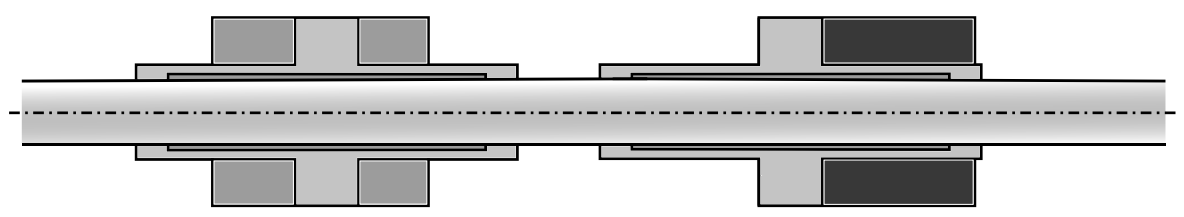

(a) One piston at the-end stop

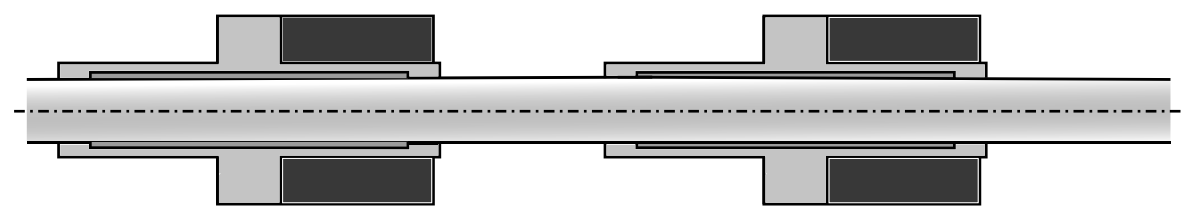

(b) Two pistons at equal side end-stops

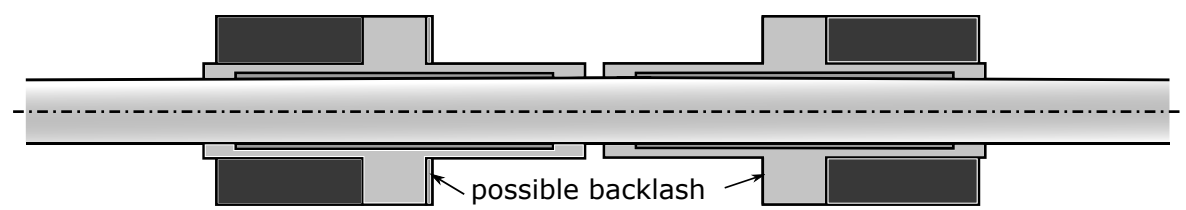

(c) Two pistons at opposed side end-stops

Figure 4.6 Infinite hydraulic stiffness, see [IV].

If one or both engaged pistons are forced against the end-stops, the pistons have mechanical contact with the cylinder casing and the hydraulic stiffness becomes infinite, i.e. the oil column with a length of $0 \mathrm{~m}$ does not influence the dynamic behavior of the system any more. This gait is therefore called "Infinite Hydraulic Stiffness".

This gait can be realized in three basically different configurations, see Figure 4.6. Forcing one piston against an end-stop, Figure 4.6a, may replace separate locking mechanisms. Forcing both pistons against end-stops as in Figure $4.6 \mathrm{~b}$ doubles transferable force. Both pistons have to be placed on the same side as otherwise backlash may be introduced into the system.

Actuators utilizing normally-engaged engaging/disengaging mechanisms may safely lock the load position bidirectionally for power-off by positioning the 
pistons against opposing end-stops as in Figure 4.6c.

\subsection{Gait: Slipping}

Slipping, relative motion between piston and rod while being engaged, is in most cases undesirable. Many considerations in the design of a linear incremental hydraulic actuator concern how to avoid slip. Slip may cause wear and reduces performance.

For designs like the one presented in Section 3.2, slip can be designed as a desired feature. Slip limits the transferable force and may thus be used as safety feature. The force where the engaging/disengaging mechanism starts to slip can be configured by the clamping pressure, see Equation 3.1, excepting the uncertainty in the friction model.

Another utilization of slip has been studied in paper [IV] and is called "Controlled Passive Damping". In this case, the gait Infinite Hydraulic Stiffness, Section 4.4, is used with reduced clamping pressure to introduce controlled passive damping into the system.

\subsection{Gait: Stepping}

This gait has been presented in [PS05] as "hydraulischer Schrittmotor", German for hydraulic stepper drive. This gait has similarities with the Inchworm Motor presented in Section 2.2.

The motion principle is shown in Figure 4.7 and Figure 4.8. The engaged cylinder, A, 0), drives the load until its end-stop while cylinder B fully retracts, 1). Cylinder B then engages, 2), followed by cylinder A disengaging, 3). Cylinder B then drives the load until its end-stop while cylinder A fully retracts, 4). Then, cylinder A engages, 5), followed by cylinder B disengaging, 6). This process repeats until the desired position has been reached.

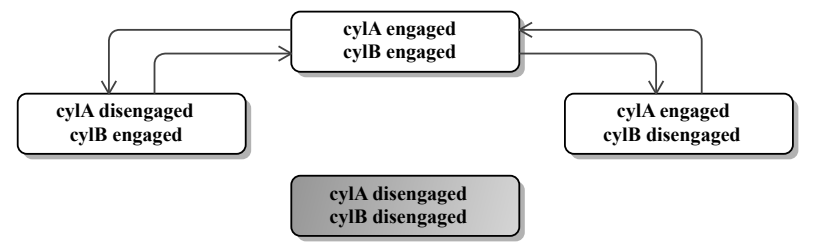

Figure 4.7 State machine: Gait: Stepping and Gait: Smooth Motion.

Characteristic of this gait is that the motion of the load stops after each stroke. In an implementation with directional control valves, the pistons hit the end stop cushions during each cycle to deaccelerate. Therefore, this gait is only 


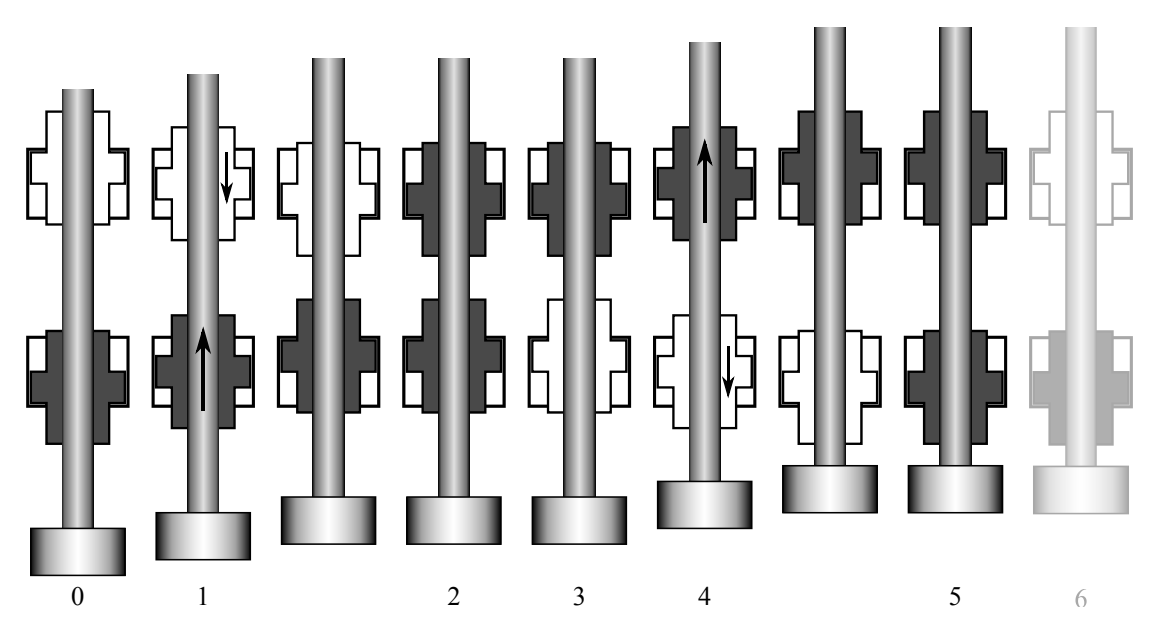

Figure 4.8 Gait: Stepping, motion principle.

The six steps of one motion cycle. The steps without numbers show the end position of the previous step. Cf. Figure 2.3, the inchworm motor motion principle. The blue/dark pistons are engaged, the white disengaged. The shaded step, 6 , is step 0 in the next motion cycle.

reasonable in applications with relatively low kinetic energy, i.e. low velocity and/or low inertia/mass. This also characterizes the actuator as discrete incremental actuator. To widen the reasonable application area, proportional valves and feedback control can be used to ensure suitable forces and thus accelerations, in particular when stopping.

The number of strokes can be used to determine the position as the stroke length of the cylinders is known. The actuator in this gait therefore realizes sensorless positioning.

Many simpler or more advanced variants of this gait exits.

\subsection{Gait: Stepping Simplified}

A simplified version of the gait Stepping, Section 4.6, can be realized with only one cylinder and one additional holding mechanism. The holding mechanism may be realized by utilizing the friction of the load, a freewheeling mechanism, or an engaging/disengaging mechanism.

In this gait, the cylinder engages, moves the load, disengages, and retracts repeatedly.

Variants of this gait are implemented in commercially available linear incre- 
mental hydraulic actuators presented in Section 2.1, the Skidding System, Figure 2.1, and the Strand Jack, Figure 2.2.

\subsection{Gait: Smooth Motion}

This gait has been studied in papers [I] and [III]. The gait is called basic gait in paper [II].

Characteristic of this gait is that at least one cylinder is engaged at all times. This gait thus has similarities with the gait Stepping, Section 4.6. Both gaits can be described by the same state machine, see Figure 4.7.

The major difference is that the gait Smooth Motion aims for continuous motion without stopping for load shifts. Velocity or force deviation caused by the load shift is also to be omitted.

The piston therefore has to synchronize with the rod when engaging. One way to realize this synchronization is that the piston engages and the increasing friction force in the clamping element passively accelerates the piston to the rod velocity. This solution may cause increased wear and the acceleration of the piston by the rod causes jerk. Another problem is that the hydraulic system may block the piston, which leads to further disturbance. One way to mitigate this problem is discussed in paper [II] and introduces lockable check-valves between the cylinder chambers.

A more advanced alternative is presented in paper [I]. There the trajectory of the retracting cylinder is coupled to the driving cylinder via a virtual gear function. This virtual gear function causes the retracting cylinder to synchronize with the driving cylinder and thus the rod before the transition phase where the cylinders change roles. The engaging is thus independent of the friction behavior of the clamping element and its uncertainty, as the retracting cylinder is already synchronized before it starts to engage.

When the retracting cylinder engages, the driving cylinder drives the full load. Should the formerly driving cylinder now disengage, the immediate transfer of the load would cause that substantial jerk to be introduced into the system. This problem is analyzed in paper [III]. Paper $[\mathrm{I}]$ proposes a solution where the load is actively shifted from the former to the later driving cylinder before disengaging. During the whole load shift the combined force of both cylinders is kept at the required force, which means it is kept constant for the simple case of constant velocity. The now retracting cylinder thus drives no load when disengaging and therefore a disturbance of the system is as good as omitted. Additionally, rod and cylinder are synchronized because of the virtual gear function. This leads to next to no jerk being introduced into the system while disengaging.

The solution proposed in paper $[\mathrm{I}]$ realizes smooth and accurate motion at 
relatively high velocity. This solution encapsulates the complexity so that the application does not have to deal with it. This solution suits arbitrary loads, including high and low inertia loads.

Figure 4.9 presents simulation results of a linear incremental hydraulic actuator raising and lowering a mass. Details are presented in paper [I]. The load is raised and then lowered $1 \mathrm{~m}$ at a constant velocity of $0.25 \mathrm{~m} / \mathrm{s}$. The first and second plots show how the cylinders drive the load and then retract, which results in the motion of the actuator. Plot three amplifies the velocity and velocity deviation. This plot shows that in this simulation the velocity deviation is $\ll 0.5 \%$ of the velocity. 


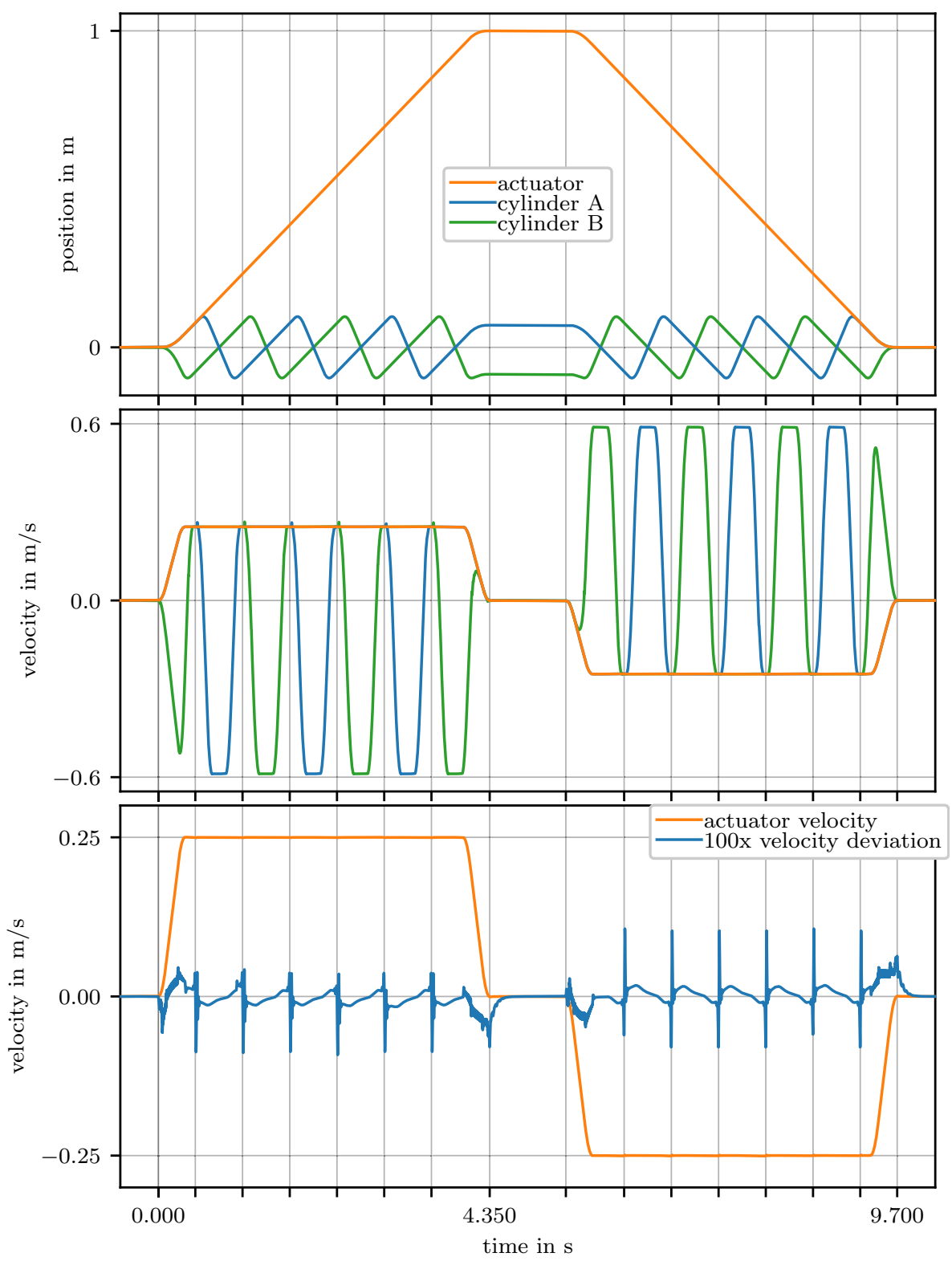

Figure 4.9 Gait: Smooth Motion.

Simulation results from the solution proposed in paper [I]. 


\subsection{Gait: Ballistic Gait}

This gait has been studied in paper [II]. In the ballistic gait, one or both cylinders engage to give the load a push, Figure 4.10. The load then carries on with its motion by means of inertia, cylinders disengaged. Characteristic is that a short strong thrust is followed by a free motion period.

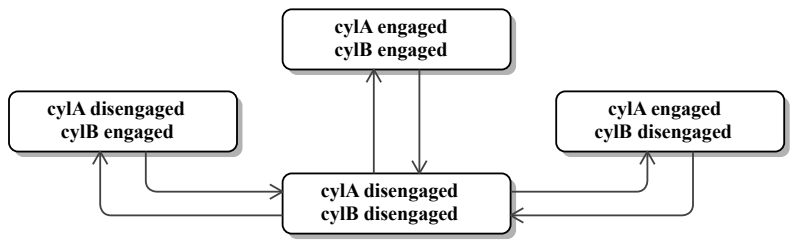

Figure 4.10 State machine: Gait: Ballistic, three variants.

The ballistic gait brings switching technology, see for example the Hydraulic Buck Converter $[\operatorname{Kog} 12]$, to the hydraulic-mechanical field. The control inputs are for example how often the thrusts are executed, how long the thrusts are, or how many cylinders engage for a thrust. The actuator may therefore realize hydraulic-mechanical pulse-frequency modulation (PFM), pulse-width modulation (PWM), and pulse-code modulation (PCM).

This gait is energy-efficient and able to recuperate energy. The drawback is that the gait does not provide smooth motion and accuracy is limited. This gait suits high-inertia loads.

Figure 4.11 presents simulation results of a linear incremental hydraulic actuator with one cylinder moving a mass horizontally. Plot 2 shows how the cylinder retracts, delivers the thrust, retracts again and so on. When the desired velocity is exceeded, the cylinder waits with the next thrust for the velocity to drop below the desired velocity. Plot 4 shows the supply flow to the valve which corresponds to the consumed power. The blue regions mark where the thrusts are delivered and thus useful work is carried out. The green regions mark the retraction phase and thus losses. These losses may be partially avoided by using a low-pressure power source for retraction. During the period marked in red the flow is negative and thus recuperating. The orange dashed line marks the flow of a conventional cylinder with equal velocity. The area between the blue and the orange dashed lines stands for the volume and thus energy saved by the linear incremental hydraulic actuator in the ballistic gait compared to a conventional cylinder. 


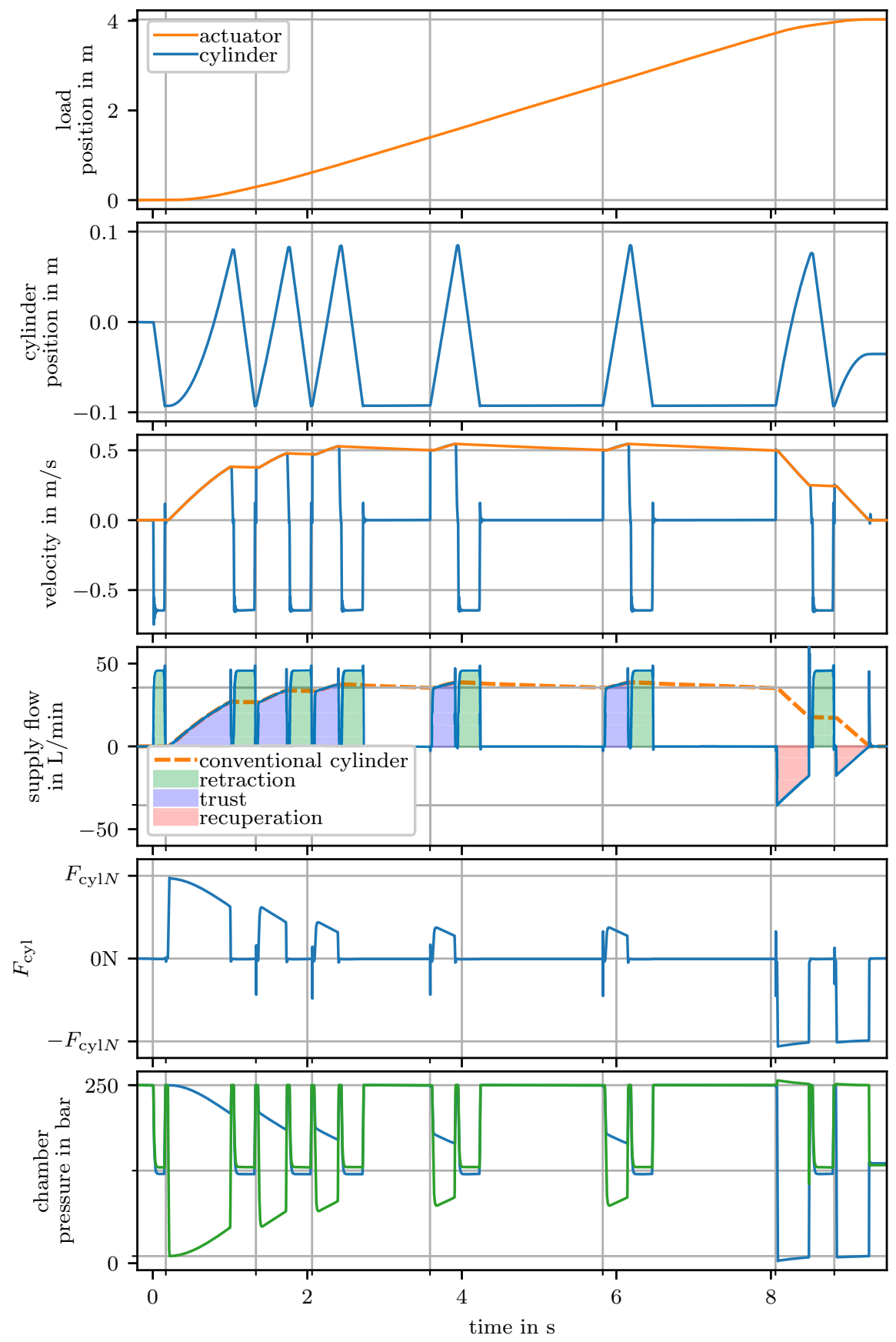

Figure 4.11 Gait: Ballistic Gait.

Simulation results from the solution proposed in paper [II]. 


\subsection{Combining Gaits}

An application may exclusively utilize one gait of a linear incremental hydraulic actuator. However, the greatest benefits are expected when different gaits are combined in an application. Gaits have strengths and weaknesses that may fit different operating points.

For example, machines may require the following working modes:

- A high performance and high accuracy work stroke with medium to infinite stroke length results from applying the Smooth Motion gait.

- A short, high-force work stroke, where the force and stiffness of two cylinders are combined, results from applying the Short Stroke, Accumulated Force gait.

- A holding period utilizing the infinite hydraulic stiffness where no power is consumed results from applying the Infinite Hydraulic Stiffness gait.

- A fast and efficient not-work stroke for retraction is realized by the Ballistic Gait.

An application field for such a working cycle might be the motion of the mounting plates of machines for advanced injection molding. 


\section{5 \\ Discussion}

This work focuses on the motion control of linear incremental hydraulic actuators. But is the concept as a whole feasible so that there is a point in working on motion control?

Strand Jacks and Skidding Systems as presented in Section 2.1 are examples of commercially available products realizing at least one gait. Drill rigs used in mining or drilling oil wells also implement linear incremental hydraulic actuators with the specialty that they build the rod from segments. Probably there also exist further implementations. Therefore, at least these gaits in these applications are feasible. Nevertheless, linear incremental hydraulic actuators are not common and cannot be purchased as commercially available off-the-shelf (COTS) component.

For a convincing cost analysis the design is insufficiently specified. A valvecontrolled conventional hydraulic cylinder system can be compared with a linear incremental hydraulic actuator implementing the gait Smooth Motion, Section 4.8. To realize an actuator implementing the gait Smooth Motion more components and perhaps more expensive components are required. On the other hand, the cost of conventional hydraulic actuators increases substantially when it comes to long stroke length, but the cost of linear incremental hydraulic actuators remains almost the same. Linear incremental hydraulic actuators therefore have a chance to be used for long strokes. For medium stroke length additional features and qualities may make linear incremental hydraulic actuators interesting in some applications as well.

\subsection{Feasibility of the Mechanical Subsystem}

Buckling is probably the main issue limiting the stroke length of conventional hydraulic cylinders. The simple design of a linear incremental hydraulic ac- 
tuator used in this thesis does not improve this issue. For tests and in some applications, buckling can be avoided by limiting the load force to pulling forces. This is generally not satisfactory. The problem is that the chosen engaging/disengaging mechanism, the hydraulically actuated hub-shaft connection, encircles the rod. The rod has therefore to be of column type and thus the buckling problem applies. An alternative is to use engaging/disengaging mechanisms which do not encircle the rod. COTS holding brakes for linear guides, Figure 3.5, are an example of such engaging/disengaging mechanisms. The rails of the guides are mounted on a support structure. Buckling therefore does not apply for the rails and thus the actuator. This work focuses on the motion control and not on the mechanical design of linear incremental hydraulic actuators. A component that is easy to analyze and is available for tests has therefore been chosen.

The engaging/disengaging mechanism is the critical component of the actuator. Two COTS components has been presented as candidates. In linear incremental hydraulic actuators, both would be used outside their usual application area. It may be assumed that for many applications these components will work satisfactory. But in general, investigations addressing the usages of these components in linear incremental hydraulic actuators are necessary. Response, slip, wear, compactness, and others are issues to look at. An alternative concept for realizing engaging/disengaging mechanisms are elastic mechanisms which may be designed by topology optimization [Sig97]. These mechanisms are produced as one part. They have no gliding or rolling parts and need no seals. Levelers and joints are formed by varying the wall thickness.

For safety reasons, applications may require the engaging/disengaging mechanisms of an actuator to be engaged when not energized (power off). The holding brakes for linear guides, Figure 3.5, are examples of such engaging/disengaging mechanisms and the concept with elastic mechanisms may also be used.

These arguments conclude that the critical mechanical components of the actuator are probably feasible. Therefore, from the mechanical perspective the actuator is also probably feasible.

\subsection{Feasibility of the Hydraulic Subsystem}

Beside the mechanical subsystem, a hydraulic subsystem is required. The hydraulic subsystem to actuate the engaging/disengaging mechanisms was investigated in paper [I] and in Section 3.2.1. The fast switching-valve FSVi 4.1 [FSVi] from Linz Center of Mechatronics GmbH provides satisfactory performance for the investigated system.

For the investigation of the cylinder motion, a common, high-performance hydraulic servo-system, see Figure 3.6, was used and investigated in paper [I]. In this solution, the mutual disturbances of the cylinders are low and therefore high control performance is expected. The drawback is the wasteful use of 
hydraulic power for retraction, where more than half of the supply flow is used without performing useful work, see paper [I].

An alternative solution is to use a second supply with low pressure for retraction to achieve more efficient actuators.

Another solution would be to reuse the flow from the driving cylinder for retraction. This can be realized by extending the idea of independent-metering valves [EP11]. The valve subsystem shall have individual control over the flow from supply to each cylinder chamber of each cylinder and further to tank. Additionally, it shall control the cross-flow between each cylinder chamber and each cylinder. This valve subsystem has to allow the supply to be connected to the A chamber of the driving cylinder, its B chamber to the B chamber of the retracting cylinder and its $\mathrm{A}$ chamber to tank. The problem is that the needed flow of both cylinders does not match. Not even the volume per stroke is the same, see paper [I]. These two solutions have not been investigated in detail.

The first discussed solution, which was also used in papers [I; III], provides a feasible hydraulic subsystem. To also reach satisfactory efficiency, further research is required.

\subsection{Feasibility of the Control Subsystem}

This analysis considers a control concept similar to that for the gait Smooth Motion, Section 4.8, presented in paper [I]. It is assumed that most of the other gaits require similar or less sophisticated control subsystems.

The control concept uses pressure sensors and position sensors for the cylinders and the actuator. The position sensors of the cylinders are short, require high resolution and fast update cycles, but have no extraordinary requirements. Some applications may require exceptionally long position sensors for the actuator position. In paper [I], a solution was presented that avoids the need for such long position sensors. The solution assumes that actuator position accuracy is required only in the area of and relative to the destination of moves, and the position sensor is therefore only realized in these areas. Candidates for such position sensors are for example contact-less magnetic linear encoders. The motion of the linear incremental hydraulic actuator can be realized with cylinder position sensors for the whole move except for the area around the destination. Some distance before reaching the destination, the position sensor signal becomes available and the actuator recalculates the trajectory to the target position. Some applications may also work entirely without actuator position sensors, for example if only relative motion is required.

The natural frequencies of linear incremental hydraulic actuators are considerably higher than those of similar conventional hydraulic actuators, in particular when retracting. Controllers with faster update cycles are therefore required. Inverse kinematic and the tracking controller are not computational intensive, 
especially when the inverse kinematic is implemented via lockup-tables. The computationally most challenging function is the actuator trajectory generator, but this function is realized in most servo controllers and solutions therefore exist.

The mechanical, the hydraulic and the control subsystems are sufficiently feasible and there is thus a point to working on motion control.

\subsection{Characteristics}

Paper [IV] states the following characteristics of linear incremental hydraulic actuators. It is assumed that the load does not change.

1. The actuator may be applicable in applications which require long or unlimited stroke.

2. The behavior of the actuator is in good approximation independent of the stroke length.

3. The behavior of the actuator is in good approximation independent of the actuator position.

4. The actuator can be designed, produced, and sold without knowing the actual stroke length.

Characteristic 1 comes with an additional cycle being just a repetition of the one before and thus there is no conceptual limit in stroke length. Nevertheless, when realizing an actuator one will experience one or the other limitation. With the discussed way to come around buckling, this limitation is overcome. One could drive a train with linear incremental hydraulic actuators. In this case, the limitation on the distance to travel is high. Characteristics 2 and 3 comes with characteristic 1. A kind of actuator for long stroke that changes behavior heavily with stroke length and actuator position is probably not practical. Linear incremental hydraulic actuators do not by the concept change their behavior with the actuator stroke length. However, they obviously change behavior with the stroke length of the cylinders used. Also, the behavior is dependent on the position of the cylinders but not on the position of the actuator, as the actuator can engage at any position and a full cycle will be the same. Characteristic 4 matches to some extent with properties of agile components. According to [Dov14] the word agile refers to operational adaptability and the sustainment of that adaptability in an uncertain and evolving environment. Only the length of the rod and maybe the length of the actuator position sensor and supply hoses etc. depend on the actuator length. The main part of the actuator, casing, cylinders, engaging/disengaging mechanisms, and control, does not depend on the stroke length. The actuator can therefore be designed, produced, and sold without knowing the actual stroke length. The stroke length can even be changed when the actuator is in use, assuming that the length of the rod can be 
changed, like for example common linear motion guides. Properties perceived by the surrounding system do not change with stroke length.

The cylinders used are short and the chamber volumes are therefore small. This results in low hydraulic capacitance of the chamber volumes, high hydraulic stiffness and consequently high natural frequencies of the system, see paper [IV]. These properties are usually perceived as positive. During retraction, the driven mass is also small and the natural frequencies are therefore particularly high. These frequencies may be in the range of the $90 \mathrm{deg}$ phase shift frequency of the valve, and may therefore cause problems for the controller, paper [I]. Increased design pressure leads to smaller components and less oil in the system, but reduces the natural frequency of the system. The natural frequency of a system with a linear incremental hydraulic actuator is high compared to the same system equipped with a conventional hydraulic cylinder. The design pressure can therefore be increased and the systems natural frequency remains within specifications, see paper [IV].

\subsection{Control Concept for the Gait Smooth Motion}

The main contribution of this work is the tracking control concept for the gait Smooth Motion, Section 4.8, presented in paper [I].

One problem addressed is the inherent complexity of the control task. A controller for that type of linear incremental hydraulic actuator has to handle and synchronize the load, two cylinders and two engaging/disengaging mechanisms. The presented solution encapsulates the internals of the linear incremental hydraulic actuator so that an application does not have to consider them. The design decision to decouple the actuator trajectory from the actual cylinder positions and engaging/disengaging states leads to narrower constraints on the actuator trajectory and thus reduced performance of the system. On the other hand, this compromise enables flexible usage which also includes the case of human in the loop.

Conventional hydraulic actuators have no velocity limit by the concept as long commonly relevant velocities are considered. The practical limits are anyhow unremarkably low. Data sheets of conventional hydraulic cylinders limit the stroke velocity to up to for example $0.5 \mathrm{~m} / \mathrm{s}$ [Bos08]. The limitation may be the dimensions of the channels in the cylinder heads/caps and line connections or considerations of the wear of the seals for this specific cylinder type. The linear incremental hydraulic actuator presented in paper [I] and outlined in Section 3.2 requires the retracting cylinder to move 2.4-times faster than the driving cylinder and thus the load. The attainable velocity is therefore considerably lower than that of conventional hydraulic cylinders, even though it is still high compared to Strand Jack, Section 2.1.2, and Skidding System, Section 2.1.1. 
The retracting cylinder has to move faster than the driving cylinder as it has to move a longer distance in the same time. The distance the actuator moves the load during one cycle is called effective stroke length. Additional to the effective stroke there is the distance required for the transition phase, for changing the motion direction and for synchronizing. When aiming for high velocity, it is critical to minimize these additional distances. The distances for changing the motion direction and for synchronizing depend on the performance of the hydraulic subsystem, in particular the valves, the controller, and the chosen retracting trajectory. Paper $[\mathrm{I}]$ presents an efficient solution for the retracting trajectory defined as a virtual gear function. The distance required for the transition phase depends on the time required for engaging and disengaging as well as the time required for the load shift. One engaging/disengaging mechanism has been analyzed in Section 3.2.1 and paper [I]. There the fast switching-valve FSVi 4.1 [FSVi] from Linz Center of Mechatronics GmbH is used to achieve short engaging and disengaging durations. The duration for the load shift depends again on the performance of the hydraulic subsystem, the controller, and the requirement for smoothness.

The impact of all these additional distances and durations depends on the effective stroke length. A longer effective stroke length allows the actuator velocity to be increased or alternatively the requirements on the components to be slackened. But increasing the effective stroke length also means increasing the stroke length of the cylinders and thus the overall size of the actuator. An alternative is to use three cylinders, but this also increases the overall size.

The factors influencing the attainable velocity also influence the efficiency of the actuator. The distances the cylinders have to move additionally to the effective stroke require flow which does not provide useful work.

The presented solution to realize the gait Smooth Motion is practical and has prospects for high performance for that kind of system. The biggest drawback is the poor energy efficiency, which requires further research. The presented solution is interesting for applications where the advantages of the system outweigh the poor energy efficiency.

\subsection{The Ballistic Gait}

The Ballistic Gait is another gait and presented in paper [II] and Section 4.9. In this gait, one or both cylinders engage to give the load a push. The load then continuous with its motion by means of inertia, cylinders disengaged. This repeating sequence of a short strong thrust followed by a free motion period realizes hydraulic/mechanic switching. This switching allows the efficiency of constant pressure systems to be increased.

Switching technology is used in electrical power systems and hydraulics [Kog12]. In electrical systems, switching frequencies beyond human perception are used. 
In most cases, the low-pass characteristic of the system prevents switching in the electrical systems from becoming noticeable in the application. In hydraulic switching technology, common switching frequencies are around $100 \mathrm{~Hz}$ and switching is noticeable mainly as noise. In the Ballistic Gait, the switching frequency ranges from a fraction of a $\mathrm{Hz}$ to a few $\mathrm{Hz}$. Humans would feel the switching as a variation in motion. The switching may also introduce oscillations in the support structure. This may be acceptable or not depending on the application.

In walking mechanics, the Froude number [WIKIFro] is used to characterize the transition from walking to running. Analysis of the Ballistic Gait, paper [II], yields a dimensionless value, calculated with an equation similar to the one used for the Froude number. In the same way as the Froude number, this dimensionless value can be used to characterize motion in the Ballistic Gait. Dimensioning linear incremental hydraulic actuators in the Ballistic Gait according to the same dimensionless value will lead to motion with the same relative variation in velocity. 


\section{6 \\ Conclusion}

In this work, a class of hydraulic actuators, the linear incremental hydraulic actuators, has been introduced. Linear incremental hydraulic actuators combine one or more short-stroke actuators, hydraulic cylinders, and two or more engaging/disengaging mechanisms into one actuator with medium, long, or even unlimited stroke length.

Outside the field of fluid power actuators, linear incremental actuators like the inchworm motor are common. In fluid power, only rotational incremental actuators, i.e. positive-displacement motors, are common. Linear incremental hydraulic actuators are nearly unknown, even though there are commercial products containing variants of linear incremental hydraulic actuators. Nevertheless, linear incremental hydraulic actuators have interesting characteristics which may be beneficial in various applications, which leads to the first research question:

\section{RQ1: What are the characteristics of a linear incremental hydraulic actuator?}

This has been investigated in paper [IV]. Section 3.1 defines what is considered to be a linear incremental hydraulic actuator. Characteristic of linear incremental hydraulic actuators is the incremental motion. The incremental motion results in the actuator being applicable for long or even unlimited stroke length. The behavior of the actuator is in good approximation independent of stroke length and actuator position. The small cylinder chamber volumes lead to low hydraulic capacitance, high hydraulic stiffness and consequently high natural frequency of the system.

Characteristic is also that the incremental motion can be accomplished in various ways. The applied patterns are called gaits and are introduced in Chapter 4 . 
For linear hydraulic actuation, hydraulic servo-systems with conventional hydraulic cylinders are currently the most prominent candidates. Linear incremental hydraulic actuators may be an attractive alternative but they are more complex and switching the load between multiple cylinders may be problematic. One obvious problem is that switching the load between multiple cylinders may introduce unacceptable jerk into the system. Smooth motion, i.e. motion without disturbing changes in velocity, jerks, is important in many applications. This leads to the second research question:

\section{RQ2: How can smooth, comparable to a conventional hydraulic servo-system, motion be realized?}

This has been investigated in papers [I] and [III]. The gait Smooth Motion as discussed in Section 4.8 is the relevant gait for realizing this motion.

It has been identified that two problems have to be solved. The first is to coordinate the cylinders' and the load's motions. Paper [I] presents a solution utilizing a virtual gear function coupling the motion of the two cylinders. The second is the shift of the load from one cylinder to the other. As investigated in paper [III], this load shift may introduce substantial jerk into the system. Paper [I] presents a solution where the force of both cylinders is controlled in a way that the sum of these forces always corresponds to the force needed to drive the load according to a given trajectory.

The resulting system realizes smooth motion. The jerk introduced into the system exists but is small and probably does not affect most applications. The realizable velocity is slower but of a similar magnitude to that of conventional hydraulic cylinders.

From the motion control perspective smooth motion can thus be realized with linear incremental hydraulic actuators and one solution has been presented.

The gait Smooth Motion is one of the possible gaits. The linear incremental hydraulic actuators used for most investigations in this work have three mechanical DoFs, two continuous and two discrete control inputs. A hydraulic servo-system with conventional hydraulic cylinder has in contrast one mechanical DoF and one continuous control input. These additional DoFs and control inputs give additional freedom for the control strategy, lead to the third research question:

\section{RQ3: How can the additional freedom be used beneficially?}

Linear incremental hydraulic actuators have additional DoFs and control inputs compared to conventional hydraulic cylinders. This additional freedom allows implementation of various gaits as introduced in Chapter 4, and is the enabler for incremental motion. The following two examples show how the freedom can be used beneficially.

The gait Smooth Motion, RQ2, enables smooth, long-distance motion. This 
gait can be combined with the gait Short Stroke, Accumulated Force, which allows twice the force for a short distance to be applied. When the motion has stopped, the gait Infinite Hydraulic Stiffness can be used to eliminate the hydraulic elasticity in the system and to lock the actuator in place for power-off. This has been investigated in papers [I] and [IV].

Another way to use this freedom is the Ballistic Gait, investigated in paper [II]. In the Ballistic Gait, one cylinder engages to give the load a push. The load then carries on with its motion by means of inertia, cylinders disengaged. This gait thus realizes hydraulic-mechanical pulse-frequency modulation (PFM), is energy-efficient and is able to recuperate energy. 


\section{Notation}

$\begin{array}{llc}{[]_{d}} & \text { desired value of [] } & \\ \delta & \text { valve's damping factor } & 1 \\ \mu & \text { friction parameter } & 1 \\ \rho_{\text {fluid }} & \text { density of the fluid } & \mathrm{kg} / \mathrm{m}^{3} \\ A_{\mathrm{c}} & \begin{array}{l}\text { effective area where } p_{\mathrm{c}} \text { acts to create the normal force } \\ \end{array} & \mathrm{m}^{2} \\ A_{\mathrm{P} i j} & \text { to create the friction force } & \mathrm{m}^{2} \\ b_{\text {clamp }} & \text { cylinder's piston area, chamber } i \text {, cylinder } j & \\ & \text { viscous friction parameter for the disengaged } & \mathrm{N} \mathrm{s} / \mathrm{m} \\ b_{\mathrm{L}} & \text { engaging/disengaging mechanisms } & \mathrm{N} \mathrm{s} / \mathrm{m} \\ b_{\mathrm{L}} & \text { effective damping } & \mathrm{N} \mathrm{s} / \mathrm{m} \\ b_{\text {cylj }} & \text { viscous friction parameter for the load } & \mathrm{N} \mathrm{s} / \mathrm{m} \\ c_{\mathrm{V}} & \text { viscous friction parameter for the cylinder } j & \frac{\mathrm{L} / \mathrm{min}}{\sqrt{\mathrm{Pa}}} \\ c_{V i S} & \text { valves flow parameter } & \frac{\mathrm{L} / \mathrm{min}}{\sqrt{\mathrm{Pa}}} \\ c_{V i T} & \text { valves flow parameter, chamber } i \text {, supply } & \frac{\mathrm{L} / \mathrm{min}}{\sqrt{\mathrm{Pa}}} \\ E & \text { valves flow parameter, chamber } i \text {, tank } & \mathrm{Pa} \\ F_{\mathrm{c} 0} & \text { fluid's bulk modulus } & \mathrm{N} \\ F_{\mathrm{c}} & \text { remaining friction force caused e.g. by scrappers } & \mathrm{N} \\ F_{\mathrm{L}} & \text { friction force generated by the clamping element } & \mathrm{N} \\ f_{\mathrm{V}} & \text { effective load force } & \mathrm{Hz} \\ F_{\text {cylj }} & \text { valve's corner frequency for small amplitudes } & \mathrm{N} \\ F_{\mathrm{disturbance}} & \text { force of cylinder } j & \mathrm{~N} \\ F_{\mathrm{d} \text { clamp } j} & \text { disturbance force } & \mathrm{N} \\ & \text { engaging/disengaging mechanisms on cylinder } j & \end{array}$




$\begin{array}{llc}m_{\mathrm{L}} & \text { effective mass / inertia } & \mathrm{kg} \\ m_{\mathrm{P} j} & \text { mass of cylinder } j & \mathrm{~kg} \\ p_{\mathrm{c} 0} & \begin{array}{l}\text { minimal pressure where the hub-shaft connection } \\ \text { starts to engage }\end{array} & \mathrm{Pa} \\ p_{\mathrm{c}} & \text { pressure applied to the clamping element } & \mathrm{Pa} \\ p_{\mathrm{L}} & \text { reduced system's load pressure } & \mathrm{Pa} \\ p_{A} & \text { pressure in chamber } A & \mathrm{~Pa} \\ p_{B} & \text { pressure in chamber } B & \mathrm{~Pa} \\ p_{S} & \text { supply pressure } & \mathrm{Pa} \\ p_{T} & \text { tank pressure } & \mathrm{Pa} \\ q_{\mathrm{L}} & \text { reduced system's load flow rate } & \mathrm{L} / \mathrm{min} \\ q_{\text {nom }} & \text { nominal flow at e.g. } 5 \text { bar or } 35 \text { bar } & \mathrm{L} / \mathrm{min} \\ T_{\mathrm{disengage}} & \text { disengaging duration, upper limit } & \mathrm{s} \\ T_{\mathrm{engage}} & \text { engaging duration, upper limit } & \mathrm{s} \\ V_{0 i j} & \text { volume of cylinder at } x_{\text {cyl }}=0 \mathrm{~m}, \text { chamber } i, \text { cylinder } j & \mathrm{~m}{ }^{3} \\ V_{A j} & \text { volume of cylinder chamber A of cylinder } j & \mathrm{~m}^{3} \\ V_{B j} & \text { volume of cylinder chamber B of cylinder } j & \mathrm{~m}^{3} \\ x_{\text {act }} & \text { position of the actuator } & \mathrm{m} \\ x_{\mathrm{cyl} j} & \text { position of cylinder } j & \mathrm{~m} \\ x_{\mathrm{Vc}} & \text { normalized vale spool position } & 1\end{array}$




\section{Abbreviations}

BDD Block Definition Diagram

COTS commercially available off-the-shelf

DDHA direct driven hydraulic actuator

DoF degree of freedom

EHA electro-hydraulic actuator

HAM hydraulic artificial muscles

HILA hydraulic infinite linear actuator

HSS hydraulic servo-system

LIHA linear incremental hydraulic actuator

PFM pulse-frequency modulation

PWM pulse-width modulation

SysML Systems Modeling Language

TDD test-driven development

VDLA variable displacement linear actuator 


\section{Glossary $^{1}$}

actuator In this work actuator shall be defined as the whole mechanism driving a load. An actuator aggregates mechanical, hydraulic, electric, sensory, and software subsystems.

Alternative Definition: "An actuator is a type of motor that is responsible for moving or controlling a mechanism or system." [WIKIAct]

Block Definition Diagram The Block Definition Diagram (BDD) is one of the Systems Modeling Language (SysML) diagram types. The Block Definition Diagram is used to model the structure of systems. [Fri+11]

commercially available off-the-shelf (COTS) "An adjective that describes software or hardware products that are ready-made and available for sale to the general public." [Webopedia]

conventional hydraulic actuator In this work conventional hydraulic actuator shall be defined as a system consisting of a conventional hydraulic cylinder, a valve system, and a control system.

conventional hydraulic cylinder In this work conventional hydraulic cylinder shall be defined as the part of a conventional hydraulic actuator that converts hydraulic pressure to mechanical force. The main components are cylinder body, piston, seals, guides, and rod. The movable piston separates the low-pressure from the high-pressure chamber. The pressures in the chambers and the areas of the piston create the mechanical force used to drive a load. They are commonly called hydraulic cylinders and occasionally also linear hydraulic motors or linear hydraulic actuators. In this work the term conventional hydraulic cylinder is used to distinguish between the hydraulic cylinders used as a component in the linear incremental hydraulic actuator and the hydraulic cylinder forming the conventional hydraulic actuator.

\footnotetext{
${ }^{1}$ Where appropriate the template for definitions according to [RS11] is used.
} 
degree of freedom (DoF) "In physics, the degree of freedom of a mechanical system is the number of independent parameters that define its configuration." [WIKI]

digital hydraulics In this work digital hydraulics shall be defined as generalization of switching hydraulics, multi-chamber hydraulic cylinder, systems utilizing multiple supply pressures and on/off valves, and similar technologies.

directional control valve "Directional control valves direct or prevent the flow through certain selected passages. They do not regulate the flow, at least as a primary function, but simply perform a switching function. As such they have a discrete number, usually two or three, of valve positions." [Mer67, page 319]

fluid power In this work fluid power shall be defined as technology to transmit power by the flow of pressurized fluid [NFPA]. This work considers only fluid power where the fluid is oil, also called hydraulics.

gait In this work gait shall be defined as the pattern of movement of linear incremental hydraulic actuators.

Alternative Definition: "Gait is the pattern of movement of the limbs of animals, including humans, during locomotion over a solid substrate." [WIKIGait]

hydraulic infinite linear actuator (HILA) Hydraulic Infinite Linear Actuator is an alternative working title for linear incremental hydraulic actuator.

hydraulics In this work hydraulics shall be defined as a synonym for fluid power whereby the fluid used is mineral, synthetic oil or alternatives. It builds primarily on hydrostatics. [NFPA]

incremental actuator In this work incremental actuator shall be defined as an actuator moving in increments which can be steps or cycles. The increments may, but do not have to, be equidistant, or defined positions. One prominent example of an incremental actuator is the stepper motor. In [Sil15], stepper motors are classified as incremental drives.

inertial frame of reference "An inertial frame of reference, in classical physics, is a frame of reference in which bodies, whose net force acting upon them is zero, are not accelerated, that is they are at rest or they move at a constant velocity in a straight line." [WIKI] 
jerk In this work jerk shall be defined as a quick, sharp, sudden movement, [OXD] or alternatively as the time derivative of acceleration and thus the third time derivative of position: $\frac{\mathrm{d}}{\mathrm{d} t} a(t)=\frac{\mathrm{d}^{3}}{\mathrm{~d} t^{3}} x(t)$.

linear incremental hydraulic actuator In this work linear incremental hydraulic actuator shall be defined as an incremental actuator for linear motion driven by fluid power.

An alternative term is hydraulic infinite linear actuator (HILA).

load In this work load shall be defined as the system driven, moved, or acted on by the actuator.

long stroke length In this work long stroke length shall be defined as the stroke length defining an actuator which is beyond the usual in that domain. The domain is linear hydraulic actuation. Beyond the usual is interpreted as not feasible, not economically acceptable, or that there is substantial derating of functionality or performance.

mechatronic adjective to Mechatronics

Mechatronics Mechatronics is a multidisciplinary field of engineering that includes among others a combination of mechanical engineering, electronics, and computer engineering [WIKI].

"A mechatronic system requires a multidisciplinary approach for its design, development, and implementation." [Sil05]

medium stroke length In this work medium stroke length shall be defined as the stroke length defining an actuator which is usual in that domain. The domain is linear hydraulic actuation.

model German: "Ein Modell (M) eines Systems (S) und eines Experiments (E) ist irgendetwas, worauf E angewendet werden kann, um Fragen über S zu beantworten. (Lecture notes Skriptum Bionik refered to [Min65])"

"We use the term model in the following sense: To an observer B, an object $\mathrm{A}^{*}$ is a model of an object $\mathrm{A}$ to the extent that $\mathrm{B}$ can use $\mathrm{A}^{*}$ to answer questions that interest him about A." [Min65]

German: "Model: Physikalisch-mathematisches Abbild eines technischen Bauelements, einer Baugruppe oder eines komplexen Systems." [VDI2206]

"A model is a representation of one or more concepts that may be realized in the physical world. It generally describes a domain of interest. A key feature of a model is that it is an abstraction that does not contain all the detail of the modeled entities within the domain of interest. Models are represented in many forms including graphical, mathematical, and 
logical representations, and physical prototypes." [Fri+11]

"A selective representation of some system that captures accurately and concisely all of its essential properties of interest for a given set of concerns." [Sel11]

"We don't see everything at once. What we do see is adjusted to the purpose and to human understanding." [Sel11]

"Reducing complexity to a human scale." unknown source

piston In this work the term piston shall be defined as a short form of piston assembly.

piston assembly In this work piston assembly or just piston shall be defined as the whole moving part of the cylinder including all permanently connected parts as there are or may be seals, a rod permanently connected to the piston, and other parts.

pneumatics In this work pneumatics shall be defined as a synonym for fluid power where the fluid used is air.

proportional valve In this work proportional valve shall be defined as a valve to control flow, whereby the control element, often a spool, can be positioned continuously within the opening range. It is assumed that the control input is an electrical signal sent from control hardware. Proportional valve is seen as a synonym for servo valve, see [Joh12].

rod In this work the term rod shall be defined as the part to which the engaging/disengaging mechanism can engage, respectively disengage from. The term is seen very general and does not assume limitations on geometry. In many cases a circular rod is assumed.

sensorless positioning In this work sensorless positioning shall be defined as positioning, where no dedicated position sensors are used to determine the position of the load.

servo valve In this work servo valve shall be defined as a synonym for proportional valve, see [Joh12].

short stroke length In this work short stroke length shall be defined as the stroke length defining an actuator which is below or in the lower range of the usual in that domain. The domain is linear hydraulic actuation. 
Systems Modeling Language "The Systems Modeling Language (SysML) is a general purpose modeling language for engineering systems." See [Fri+11]

test-driven development (TDD) "Test-driven development is a software development process that relies on the repetition of a very short development cycle: Requirements are turned into very specific test cases, then the software is improved to pass the new tests, only." [WIKI]. See also [Gre11]. 


\section{Bibliography}

[Amo16] Astor Garcia Amor. "Friction, a Limiting Property in Controlled Motion." Bachelor Thesis. Division of Fluid, Mechatronic Systems, Department of Management, and Engineering, Linköping University, 2016.

[And+05] Torben Ole Andersen, Michael Rygaard Hansen, Henrik Clemmensen Pedersen, and Finn Conrad. "On the Control of Hydraulic Servo Systems: Evaluation of Linear and Non-linear Control Schemes." In: Proceedings of The Ninth Scandinavian International Conference on Fluid Power, SICFP05. 2005.

[And+15] Torben Andersen, Henrik Pedersen, Michael Bech, and Lasse Schmidt. "A low order adaptive control scheme for hydraulic servo systems." In: 2015 International Conference on Fluid Power and Mechatronics (FPM). Institute of Electrical and Electronics Engineers (IEEE), 2015. DOI: $10.1109 / \mathrm{fpm}$. 2015.7337292.

[Bos08] Bosch Rexroth AG. Data Sheet: Hydraulic Cylinders, Series CD210 / CG210. RE 17017/08.08, from https://www.boschrexroth.com/. 2008.

[BRSS] Website of Bosch Rexroth AG - Skidding Systems. https://www.boschrexroth.com/en/xc/industries/machinery-applications-and-engineering/offshore/products-and-solutions/skidding-systems/skidding, visited 2017-07-31.

[Cet07] Sabri Cetinkunt. Mechatronics. John Wiley, 2007. ISBN: 047147987x.

[Cla94] Don P. Clausing. Total Quality Development: A Step-ByStep Guide to World-Class Concurrent Engineering. New York: ASME Press, 1994. ISBN: 978-0791800355. 
[CSM] Website of NoMagic - Cameo Systems Modeler. http://www.nomagic.com/products/cameo-systems-modeler.html, visited 2017-10-21.

[Dov14] Rick Dove. "Agile Systems-Engineering and Agile-Systems Engineering." In: INSIGHT - International Council on Systems Engineering (INCOSE) Volume 17.Issue 2 (2014).

[EatonCMA200] CMA200 - Advanced Independent-Metering Mobile Valve. EATON CMA200 Technical Document E-VLMB-BB002-E1 September 2016. EATON Hydraulics Group. 2016.

[ENGELDUO] ENGEL. DUO. Product Data Sheet, https://www.engelglobal.com/. 2016.

[ENK10] Björn Eriksson, Peter Nordin, and Petter Krus. "Hopsan NG, A C++ Implementation using the TLM Simulation Technique." In: Proceedings of The 51st Conference on Simulation and Modelling (SIMS2010). 2010.

[EP11] Björn Eriksson and Jan-Ove Palmberg. "Individual Metering Fluid Power Systems: Challenges and Opportunities." In: Proceedings of the Institution of Mechanical Engineers. Part I, Journal of Systems and Control Engineering 225.12 (2011), pp. 196-211. ISSN: 0959-6518. DOI: 10.1243/ 09596518 JSCE1111.

[EpSJ] Website of ENERPAC - Strand Jacks. http://www.enerpac.com/en/heavy-lifting-technology/strand-jacks, visited 2017-10-21. (Visited on 03/02/2017).

[EpSS] Website of ENERPAC - Skidding System. http://www.enerpac.com/-en/-heavy-lifting-technology/skidding-system, visited 2017-10-21.

[ETP] Website of ETP Transmission AB. http://www.etp.se/, visited 2017-10-21.

[ETPOCT] ETP Transmission AB. ETP-OCTOPUS - Datasheet for Octopus. Tech. rep.

[Fri+11] Sanford Friedenthal, Alan Moore, and Rick Steiner. A Practical Guide to SysML. 2nd. Morgan Kaufmann, OMG, 2011. ISBN: 978-0123852069.

[FSVi] Linz Center of Mechatronics GmbH - Hydraulic Drives. FSVi 4.1 Datasheet - Fast Switching Valve Technolog. http://www.lcm.at/. 2016. 
[GKS14] Christoph Gradl, Ivo Kovacic, and Rudolf Scheidl. "Development of an Energy Saving Hydraulic Stepper Drive." In: Proceedings of the 8th FPNI PhD Symposium on Fluid Power. FPNI2014-7809. Lappeenranta, Finland, 2014. DOI: 10.1115/FPNI2014-7809.

[GPS16] Christoph Gradl, Andreas Plöckinger, and Rudolf Scheidl. "Sensorless position control with a hydraulic stepper drive - Concept, compression modeling and experimental investigation." In: Mechatronics 35 (2016), pp. 91-101. ISSN: 09574158. DOI: $10.1016 / \mathrm{j}$.mechatronics.2016.01.004.

[Gra16] Christoph Gradl. "Hydraulic Stepper Drive - Conceptual Study, Design and Experiments." PhD thesis. 2016. DoI: $10.13140 / \mathrm{rg} \cdot 2 \cdot 2.12508 .18560$.

[Gre11] James W. Grenning. Test Driven Development for Embedded C. 1st ed. O'Reilly, 2011. ISBN: 9781934356623.

[GS17] Christoph Gradl and Rudolf Scheidl. "Performance of an Energy Efficient Low Power Stepper Converter." In: Energies 10.4 (2017), p. 445. DOI: 10.3390/en10040445.

[GS94] Heinz Gall and Kurt Senn. "Freilaufventile - Ansteuerungskonzept zur Energieeinsparung bei hydraulischen Linearantrieben." In: Olhydraulik und Pneumatik 38.1 (1994), pp. 38-44.

[HI85] J.A. Holton and J.C. Inman. "Piston-Cylinder Assembly." US 4526086 A. US Patent. 1985.

[HS17] Kim Heybroek and Mika Sahlman. "A Hydraulic Hybrid Excavator based on Multi-Chamber Cylinders and Secondary Control." In: Proceedings of the 15th Scandinavian International Conference on Fluid Power, SICFP'17. 2017.

[II01] Jaroslav Ivantysyn and Monika Ivantysynova. Hydrostatic Pumps and Motors: Principles, Design, Performance, Modelling, Analysis, Control and Testing. Ed. by J. Saketharaman. 1. English ed. Akademia Books International, 2001. ISBN: 8188305081.

[JK04] Mohieddine Jelali and Andreas Kroll. Hydraulic Servosystems: Modelling, Identification and Control. Advances in Industrial Control. Springer, 2004. ISBN: 978-1-4471-1123-8.

[Joh12] Jack L. Johnson. "What is the difference between a servovalve and a proportional valve." In: Hydraulics and Pneumatics 65.8 (2012), p. 18. ISSN: 0018814X. 
[Kal12] Eberhard Kallenbach. Elektromagnete: Grundlagen, Berechnung, Entwurf und Anwendung. Wiesbaden: Vieweg+Teubner Verlag, 2012. ISBN: 978-3834809681.

[KM15] Janne Koivumäki and Jouni Mattila. "Stability-Guaranteed Force-Sensorless Contact Force/Motion Control of HeavyDuty Hydraulic Manipulators." In: IEEE Transactions on Robotics 31.4 (2015), pp. 918-935. ISSN: 15523098.

[KM17] Janne Koivumäki and Jouni Mattila. "Stability-Guaranteed Impedance Control of Hydraulic Robotic Manipulators." In: IEEE/ASME Transactions on Mechatronics 2 (2017), p. 601. ISSN: 1941-014X.

[Kog12] Helmut Kogler. "The Hydraulic Buck Converter - Conceptual Study and Experiments." ISBN: 978-3990330593. PhD thesis. Johannes Kepler Universität Linz, Austria, 2012.

[Koi16] Janne Koivumäki. "Stability-Guaranteed Nonlinear ModelBased Control of Hydraulic Robotic Manipulators." PhD thesis. Tampere University of Technology, 2016.

[KSK99] Andreas Kugi, Kurt Schlacher, and Georg Keintzel. "Position Control and Active Eccentricity Compensation in Rolling Mills." In: Automatisierungstechnik 47.8 (Aug. 1999), pp. 342-349.

[Kug00] Andreas Kugi. Non-linear Control Based on Physical Models: Electrical, Mechanical and Hydraulic Systems. Lecture Notes in Control and Information Sciences 260. Springer, 2000. ISBN: 1-85233-329-4.

[KW16] Giacomo Kolks and Jürgen Weber. "Modiciency - Efficient industrial hydraulic drives through independent metering using optimal operating modes." In: Proceedings of the 10th International Fluid Power Conference (10. IFK). http://nbnresolving.de/urn:nbn:de:bsz:14-qucosa-199423. 2016.

[Lib03] Daniel Liberzon. Switching in Systems and Control. Systems \& Control: Foundations \& Applications. Birkhäuser Boston, Inc., Boston, MA, 2003. ISBN: 0-8176-4297-8.

[Lin+09] Matti Linjama, H-P Vihtanen, Annina Sipola, and M Vilenius. "Secondary Controlled Multi-Chamber Hydraulic Cylinder." In: The 11th Scandinavian International Conference on Fluid Power, SICFP09. 2009.

[Lin11] Matti Linjama. "Digital Fluid Power - State Of The Art." In: The 12th Scandinavian International Conference on Fluid Power, SICFP2011. 2011. 
[Mer67] Herbert E. Merritt. Hydraulic Control Systems. Wiley, 1967. ISBN: 0471596175 .

[Min65] Marvin L. Minsky. Matter, Mind and Models. Online, accessed 2017-10-21. http://groups.csail.mit.edu/medg/people/doyle/gallery/minsky/mmm.html. 1965.

[MLP13] Tatiana Minav, Lasse I. E. Laurila, and Juha J. Pyrhönen. "Relative position control in an electro-hydraulic forklift." In: International Review of Automatic Control 6.1 (2013), pp. 54-61. ISSN: 19746059.

[MP17] Tatiana Minav and Matti Pietola. "A study on thermal behavior of pump-controlled actuator." In: Proceedings of the 15th Scandinavian International Conference on Fluid Power, SICFP'17. 2017.

[Mur98] Hubertus Murrenhoff. Grundlagen der Fluidtechnik - Teil1: Hydraulik. 2nd. Aachen: Mainz, 1998. ISBN: 3896532596.

[NFPA] National Fluid Power Association. What is fluid power? http://www.nfpa.com/fluidpower/whatisfluidpower.aspx, Online visited 2017-10-21.

[OXD] Oxford University Press. Oxford Dictionaries. https://en.oxforddictionaries.com/, Online visited 2017-10-21.

[PGS16] Andreas Plöckinger, Christoph Gradl, and Rudolf Scheidl. "High Accuracy Sensorless Hydraulic Stepping Actuator." In: Proceedings of The Eight Workshop on Digital Fluid Power, May 24-25, 2016, Tampere, Finland. Tampere: Tampere University of Technology - Department of Intelligent Hydraulics and Automation, May 2016.

[PS05] Tilo Pfeifer and Robert Schmitt. Autonome Produktionszellen. Komplexe Produktionsprozesse flexibel automatisieren (VDI-Buch). ISBN-13: 978-3540292142. SpringerVerlag GmbH, Nov. 11, 2005. ISBN: 978-3-540-29214-2.

[RB78] G. Reymann and P. Baumeister. "Hydraulischer Linearmotor." DE 2649958 A1. German Patent. 1978.

[Rei97] Donald Reinertsen. Managing the Design Factory: A Product Developer's Toolkit. New York: Free Press, 1997. ISBN: 9780684839912.

[RS09] Chris Rupp and SOPHISTen. Requirements-Engineering und -Management. 5. Auflage. Hanser, 2009. ISBN: 9783446418417.

[RS11] Chris Rupp and SOPHISTen. Requirements Engineering and Management (EN). online available from: http://www.sophist.de/, this is the englich version of [RS09]. 2011. 
[Ryd16] Karl-Erik Rydberg. Hydraulic Servo Systems: Dynamic Properties and Control. http://urn.kb.se/resolve?urn=urn:nbn:se:liu:diva-132396. 2016. ISBN: 9789176856208.

[RZ17] Gerhard Rath and Emil Zaev. "Optimal Control for Hydraulic System With Separate Meter-In and Separate MeterOut." In: Proceedings of the 15th Scandinavian International Conference on Fluid Power, SICFP'17. 2017.

[Sel11] Bran Selic. "Abstraction Patterns in Model-Based Engineering." In: 5th MODPROD Workshop on ModelBased Product Development. http://www.modprod.liu.se/MODPROD2011/1.252942/modprod2011-day2-talk1-keynote-Bran-Selic-Abstraction.pdf. Linköping, Sweden, 2011.

[Sig97] Ole Sigmund. "On the Design of Compliant Mechanisms Using Topology Optimization." In: Mechanics of Structures and Machines 25.4 (1997), pp. 493-524. DOI: $10.1080 /$ 08905459708945415.

[Sil05] Clarence W de Silva. Mechatronics: An Integrated Approach. CRC Press, 2005. ISBN: 0849312744.

[Sil15] Clarence W. de Silva. Sensors and Actuators. Taylor \& Francis, 2015. ISBN: 9781466506824.

[Sli17] Jonathon Slightam. Project 16MA1: Efficient, Integrated, Freeform Flexible Hydraulic Actuators. http://nfpahub.com/events/wp-content/uploads/sites/2/2017/04/CCEFP-Project-16MA1-IU-Summit-2017.pdf. May 2017.

$[$ Sou +17$] \quad$ Tom Sourander, Matti Pietola, Tatiana Minav, and Henri Hänninen. "Sensorless position estimation of simulated direct driven hydraulic actuators." In: Proceedings of the 15th Scandinavian International Conference on Fluid Power, SICFP'17. 2017.

[Sto+07] Dan Stoianovici, Alexandru Patriciu, Doru Petrisor, Dumitru Mazilu, and Louis Kavoussi. "A New Type of Motor: Pneumatic Step Motor." In: IEEE/ASME Transactions on Mechatronics 12.1 (2007), pp. 98-106. ISSN: 1083-4435. DOI: 10.1109/tmech. 2006.886258.

[Suh90] Nam Pyo Suh. The Principles of Design. Oxford University Press, 1990. ISBN: 0195043456.

[Thu+16] Prasanth Thummala, Henrik Schneider, Zhe Zhang, Michael A. E. Andersen, and Rahimullah Sarban. "New Incremental Actuators Based on Electroactive Polymer: Conceptual, Control, and Driver Design Considerations." In: IEEE/ASME Transactions on Mechatronics 21.3 (2016), pp. 1496-1508. DOI: $10.1109 /$ tmech.2016.2533667. 
[Tiw+12] Rashi Tiwari, Michael A Meller, Karl B Wajcs, Caris Moses, Ismael Reveles, and Ephrahim Garcia. "Hydraulic Artificial Muscles." In: Journal of Intelligent Material Systems and Structures 23.3 (2012), pp. 301-312. DOI: 10.1177 / $1045389 \times 12438627$.

[UE12] Karl T. Ulrich and Steven D. Eppinger. Product Design and Development. 5th ed. McGraw-Hill, 2012. ISBN: 9780071086950.

[Wat09] John Watton. Fundamentals of Fluid Power Control. Cambridge University Press, 2009. ISBN: 9780521762502.

[VDI2206] VDI 2206 - Entwicklungsmethodik für mechatronische Systeme. 2004.

[Webopedia] Webopedia. Webopedia: Online Tech Dictionary. http://www.webopedia.com/, Online.

[Vie80]

[WIKI]

[WIKIAct] Wikipedia. Actuator - Wikipedia, The Free Encyclopedia. https://en.wikipedia.org/w/index.php?title=Actuator\&oldid=785277694, Online; accessed 2017-06-14.

[WIKIFro] Wikipedia. Transition from walking to running - Wikipedia, The Free Encyclopedia. https://en.wikipedia.org/w/index.php?title=Transition_from_walking_to_running\&oldid$=780238890$, Online; accessed 2017-06-14.

[WIKIGait] Wikipedia. Gait - Wikipedia, The Free Encyclopedia. https://en.wikipedia.org/w/index.php?title=Gait\&oldid=780297279, Online; accessed 2017-06-14.

[WIKIIWM] Wikipedia. Inchworm motor - Wikipedia, The Free Encyclopedia. https://en.wikipedia.org/w/index.php?-title=Inchworm_motor\&oldid $=609421460$, Online; accessed 27June-2017.

[Wit+95] Carlos Canudas de Wit, Hans Olsson, Karl Johan Åström, and Pablo Lischinsky. "A New Model for Control of Systems with Friction." In: Institute of Electrical and Electronics Engineers. Transactions on Automatic Control 40.3 (1995), p. 419. ISSN: 00189286. DOI: 10.1109/9.376053. 
[WLT13] Edward Williams, Philip Loveday, and Nico Theron. "Design of a Large-Force Piezoelectric Inchworm Motor with a Force Duplicator." In: 2013 6th Robotics and Mechatronics Conference (RobMech). Durban, South Africa: IEEE, 2013, p. 46. ISBN: 9781479915187. DOI: 10.1109/robomech. 2013. 6685490 .

[WPS15] Bernd Winkler, Andreas Plöckinger, and Rudolf Scheidl. "State Of The Art In Digital Valve Technology." In: PROCEEDINGS - The Seventh Workshop on Digital Fluid Power. 26th - 27th February 2015. Linz, Austria, 2015, pp. 151-163.

[ZIM] ZIMMER GROUP. Hydraulically actuated clamping and braking element, Series KBHS. Tech. rep. http://www.zimmer-group.de/, visited 2017-09-10.

\section{Appended Papers}

$[\mathrm{I}]$

[II]

[III]

[IV]
Martin Hochwallner, Lie Pablo Grala Pinto, and Petter Krus. "Tracking Control for High Performance Motion of an Hydraulic Infinite Linear Actuator." In: submitted to IEEE/ASME Transactions on Mechatronics (2017).

Martin Hochwallner and Petter Krus. "Hydraulic Infinite Linear Actuator - The Ballistic Gait - Digital HydroMechanical Motion." In: Proceedings of the 15th Scandinavian International Conference on Fluid Power, SICFP'17. 2017.

Martin Hochwallner and Petter Krus. "Motion Control Concepts for the Hydraulic Infinite Linear Actuator." In: Proceedings of the 9th FPNI PHD Symposium on Fluid Power. Florianopolis, Brazil, 2016. ISBN: 978-0-7918-5047-3. DOI: 10.1115/FPNI2016-1523.

Martin Hochwallner, Magnus Landberg, and Petter Krus. "The Hydraulic Infinite Linear Actuator - properties relevant for control." In: Proceedings of the 10th International Fluid Power Conference (10. IFK). Vol. 3. http://nbnresolving.de/urn:nbn:de:bsz:14-qucosa-200646. Dresden, Germany, 2016, pp. 411-424. 


\section{Not Appended Papers}

[1]

$[2]$

$[3]$

$[4]$

$[5]$

[6]
Martin Hochwallner, Matthias Hörl, Stefan Dierneder, and Rudolf Scheidl. "Some Aspects of SysML Application in the Reverse Engineering of Mechatronic Systems." In: Computer Aided Systems Theory, EUROCAST 2011 - 13th International Conference, Revised Selected Papers. Vol. LNCS 6928. Lecture Notes in Computer Science. ISSN: 03029743 16113349. 2011, pp. 81-88. ISBN: 9783642275784. DOI: 10 . 1007/978-3-642-27579-1_11.

Matthias Hörl, Martin Hochwallner, Stefan Dierneder, and Rudolf Scheidl. "Integration of SysML and Simulation Models for Mechatronic Systems." In: Computer Aided Systems Theory, EUROCAST 2011 - 13th International Conference, Revised Selected Papers. Vol. LNCS 6928. Lecture Notes in Computer Science. ISSN: 03029743 16113349. 2011, pp. 8996. ISBN: 9783642275784. DOI: 10.1007/978-3-642-27579$1 \_12$.

Gernot Grabmair, Simon Mayr, Martin Hochwallner, and Markus Aigner. "Model based control design - A free toolchain." In: 2014 European Control Conference (ECC). Institute of Electrical and Electronics Engineers (IEEE), 2014. ISBN: 978-3-9524269-1-3. DOI: 10.1109/ecc. 2014.6862509.

Martin Hochwallner and Stefan Fragner. Experience made in Model Based Design with the Tool X2C in the Field of Controller Design in a Mechatronic Product Development Environment. Presentation at the 8th MODPROD Workshop 2014, in Linköping, Sweden. 2014.

Magnus Landberg, Martin Hochwallner, and Petter Krus. "Novel Linear Hydraulic Actuator." In: 2015 Proceedings of the ASME/BATH 2015 Symposium on Fluid Power and Motion Control (FPMC2015). 2015. ISBN: 978-0-7918-5723-6. DOI: $10.1115 / \mathrm{fpmc} 2015-9604$.

Liselott Ericson, Samuel Kärnell, and Martin Hochwallner. "Experimental Investigation of a Displacement-controlled Hydrostatic Pump/Motor by Means of Rotating Valve Plate." In: Proceedings of the 15th Scandinavian International Conference on Fluid Power, SICFP'17. 2017. 


\section{Papers}

The papers associated with this thesis have been removed for copyright reasons. For more details about these see:

http:// urn.kb.se/ resolve?urn=urn:nbn:se:liu:diva-142264 